\title{
The PHENOLEO project or how to separate and add-value to phenolic compounds present in rapeseed and sunflower meals
} \author{
and Sylvie Dauguet ${ }^{6, *}$ \\ ${ }^{1}$ CIRAD, UMR IATE, F-34398 Montpellier, France \\ 2 IATE, Univ. Montpellier, CIRAD, INRAE, Institut Agro, Montpellier, France \\ ${ }^{3}$ INRAE UR1268 BIA, F-35653 Le Rheu, France \\ ${ }^{4}$ UMR MoSAR, AgroParisTech INRAE, 75005 Paris, France \\ 5 INRAE UR1268 BIA, F-44316 Nantes, France \\ 6 TERRES INOVIA, Parc Industriel-11 Rue Monge, 33600 Pessac, France \\ 7 OLEAD, Parc Industriel-11 Rue Monge, 33600 Pessac, France
}

Oscar Laguna ${ }^{1,2}$, Sylvain Guyot ${ }^{3}$, Xiaoxi $\mathrm{Yu}^{3}$, Laurent-Philippe Broudiscou ${ }^{4}$, Patrick Chapoutot ${ }^{4}$, Véronique Solé-Jamault ${ }^{5}$, Marc Anton ${ }^{5}$, Alain Quinsac ${ }^{6}$, Anne-Gaëlle Sicaire ${ }^{6}$, Frédéric Fine ${ }^{6}$, Morgane Citeau $^{7}$, Erwann Durand ${ }^{1,2}$, Abdellatif Barakat ${ }^{2}$, Pierre Villeneuve ${ }^{1,2}$, Jérôme Lecomte ${ }^{1,2}$

Received 16 June 2020 - Accepted 8 October 2020

\begin{abstract}
Rapeseed and sunflower meal are mainly used as animal feed but they can also be considered as a potential source of bioactive phenolic compounds. However, the desolventization/toasting processes that are needed to produce these meals might influence concentration and chemical structure of phenolic compounds, and change their bioactive properties. Moreover, the recovery processes of these molecules from meals are based on the use of solvent that generates effluents and might affect the integrity of the other constituents of the meals. Knowing this, the PHENOLEO project, funded by the SAS PIVERT, was a research program based on the biorefinery of rapeseed and sunflower meals that aimed to develop new routes of valorization of these materials mostly by the separation and valorization of their simple phenolic compounds. Thus, we decided to focus this study on the impact of the desolventization process on the biochemical composition of meals, the separation process of their simple phenolic compounds, the production of phenolic acids from meals and the potential valorization routes of the phenolic fraction.
\end{abstract}

Keywords: rapeseed meal / sunflower meal / phenolic compounds / biorefinery

\begin{abstract}
Résumé - Le projet PHENOLEO ou comment séparer et valoriser les composés phénoliques présents dans les farines de colza et tournesol. Les tourteaux de colza et de tournesol sont principalement utilisés pour l'alimentation animale, mais ils peuvent également être considérés comme une source potentielle de composés phénoliques aux propriétés bioactives. Cependant, les procédés de désolvantation / toastage qui sont nécessaires pour produire ces tourteaux pourraient influencer la concentration et la structure chimique des composés phénoliques induisant une possible modification de leurs propriétés bioactives. De plus, les procédés de récupération de ces molécules à partir de ces tourteaux reposent sur l'utilisation de solvants qui génèrent des effluents et pourraient affecter l'intégrité des autres constituants contenus dans ces matières premières. Dans ce contexte, le projet PHENOLEO, financé par la SAS PIVERT, était un programme de recherche basé sur la bioraffinerie des tourteaux de colza et tournesol visant à développer de nouvelles voies de valorisation de ces matières premières en réalisant la séparation et la valorisation de leurs composés phénoliques simples. Ainsi, cette étude a focalisé sur l'impact des procédés de désolvantation sur la composition biochimique des tourteaux, les procédés de séparation des composés
\end{abstract}

\footnotetext{
Th Contribution to the Topical Issue "Technological challenges in oilseed crushing and refining / Défis technologiques de la trituration et du raffinage des oléagineux".

*Correspondance: s.dauguet@terresinovia.fr
} 
phénoliques simples présents dans les tourteaux, la production d'acides phénoliques par voie enzymatique et leurs valorisations potentielles.

Mots clés : tourteau de colza / tourteau de tournesol / composés phénoliques / bioraffinage

\section{Introduction}

Rapeseed (Brassica napus L.) and sunflower (Helianthus annuus L.) are two oleaginous plants grown primarily to produce vegetable oil which is mainly used for human consumption or for biofuel production (Borredon et al., 2011; Fine et al., 2015). Moreover, the main co-products resulting from the crushing, de-oiling and desolventization/toasting processes of these seeds are their meals. In 2019, worldwide production of rapeseed meal (RSM) and sunflower meal (SFM) were estimated at 33.0 and $22.2 \mathrm{Mt}$, respectively (http:// www.indexmundi.com/agriculture/). These heterogeneous raw materials are mainly used as animal feed because of their high protein content which is around 38\% DM (dry matter) for RSM, 31\% DM for SFM and 39.5\% DM for dehulled SFM (González-Pérez and Vereijken, 2007; Ivanova et al., 2016, Terres Inovia, 2019). However, RSM and SFM also contain interesting bioactive molecules such as phenolic compounds (PC) which are present as simple and extractable PC, mainly located in the kernel or as hardly extractable or bound polyphenols, concentrated in the hull (Amarowicz et al., 2000; Weisz et al., 2009; Pająk et al., 2014; Laguna et al., 2018; Fig. 1). The total simple phenolic compound (TSPC) content in RSM and SFM is around 2\% DDM (defatted dry matter) and 4\% DDM, respectively (Baumert et al., 2005; Weisz et al., 2009). Moreover, regarding the simple PC present in RSM, they are mainly sinapic acid esters with sinapine, the choline ester of sinapic acid, as the main ester that represents around $80 \%$ of the TSPC content (Baumert et al., 2005; Milkowski and Strack, 2010; Siger et al., 2013). Furthermore, the major bound PC in rapeseed hulls are mostly tannins and their content may exceed $2 \mathrm{~g} / 100 \mathrm{~g}$ of defatted dry hulls (Amarowicz et al., 2000). On the other hand, in SFM, simple PC are mainly caffeic acid esters with 5-caffeoylquinic acid (or chlorogenic acid, the quinic ester of caffeic acid) accounting for around $70 \%$ of the TSPC content (Weisz et al., 2009; Szydłowska-Czerniak et al., 2011; Guo et al., 2013). There is no much literature data regarding the bounded PC in sunflower hulls but, in the whole seed, they are mainly flavonoids and they account for around $4.3 \mu \mathrm{g} / \mathrm{g}$ DM (Pająk et al., 2014).

These naturally occurring molecules are known to be bioactive and multifunctional compounds exhibiting antioxidant (Dimitrios, 2006; Kreps et al., 2014), anti-UV (Peyrot et al., 2020) and antimicrobial activities (Ouerghemmi et al., 2017) to name a few. Knowing this, they can find applications directly or after modifications in many fields such as in food, health and cosmetic products (Kikuzaki et al., 2002; Shahidi and Ambigaipalan, 2015). For example, previous studies have shown the protective effect of ferulic acid for the preservation of some food matrices (e.g. oranges, biscuits, soybean oil, etc.) which is mainly associated with its antioxidant properties (Kumar and Pruthi, 2014). Furthermore, Lin et al. (2005) reported the antioxidant and anti-UV properties of ferulic acid and demonstrated that its association with vitamin $\mathrm{E}$ and vitamin $\mathrm{C}$ in a topical formulation provided about 4 to 8 fold higher protection against solar-simulated radiation damage. Regarding this matter, recent studies have also suggested that some sinapic acid derivatives, such as dehydrodiethylsinapate (Horbury et al., 2020) or sinapic-acid-based octinoxate analogues (Peyrot et al., 2020), are good candidates to be used as UV filters and antioxidants in sunscreen lotions. On the other hand, some phenolics can also be used as precursors of polymers for food packaging. Indeed, Reano et al. (2015), Diot-Néant et al. (2017) and Hollande et al. (2018) demonstrated that different biobased bis-aryl esters of dihydroferulic acid or dihydrosinapic acid could be used as monomers in various types of polymerization systems with the resulting polymers displaying high antioxidant activities and high thermal stabilities. In addition, Aouf et al. (2016) showed that canolol (2,6-Dimethoxy-4-vinylphenol, the decarboxylation product of sinapic acid) could be used as the precursor of bio-based epoxy resins prepolymers.

In this context, RSM and SFM could be valorized and used as a source of bioactive phenolic compounds. However, the desolventization/toasting process that are needed to produce the meals might impact concentration and chemical structure of these molecules, and change their bioactive properties (Zago et al., 2015b). Moreover, phenolic compounds can oxidize in RSM and SFM, enzymatically or in an alkaline medium, and form $o$-quinones and phenolic radicals that rapidly evolve towards complex oxidation products. Quinones and radicals can also react with the amino acids of the meal proteins, causing browning and changes in their organoleptic characteristics and techno-functional properties (Ozdal et al., 2013). Nevertheless, these $o$-quinones/proteins association also leads to the reduction of simulated degradation of proteins by rumen microorganisms meaning that phenolic compounds could possibly be used as tanning agents in order to replace formaldehyde (Hernández-Jabalera et al., 2015; Bongartz et al., 2018). Indeed, the lower rumen degradability of proteins is primarily tanned by formaldehyde, which reacts primarily with some amino acids to form methylene bonds that cause crosslinking of proteins (Barry, 1976). However, the social demand for the most possible natural compounds, plus the risks associated with the handling of formaldehyde during tanning favored the research for alternative tanning agents of vegetable origin. Thus, phenolic compounds present in RSM and SFM could also be valorized in the form of tanning agents.

Hence, in order to add-value to all the constituent present in these oleaginous meals either for food/feed or chemical applications, it is necessary to partially or totally separate the phenolic compounds beforehand. Thus, the PHENOLEO project, funded by the SAS PIVERT, was a research program based on the biorefinery of rapeseed and sunflower meals that aimed to develop new routes of valorization of these meals mostly by the separation and valorization of their simple phenolic compounds. Indeed, the separation of these molecules could allow increasing the nutritional qualities of 

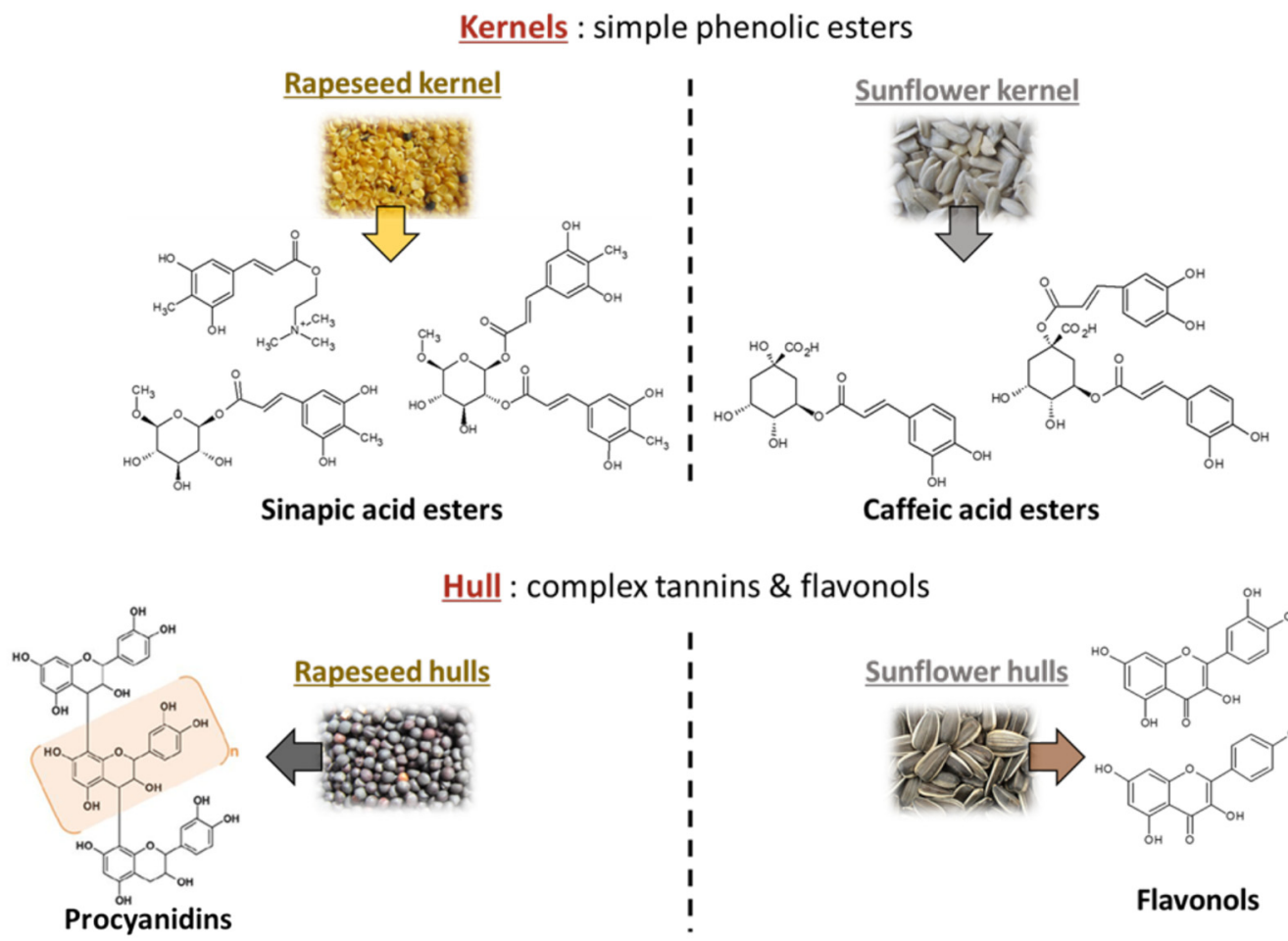

Hull : complex tannins \& flavonols

I
I
I
I
I
!

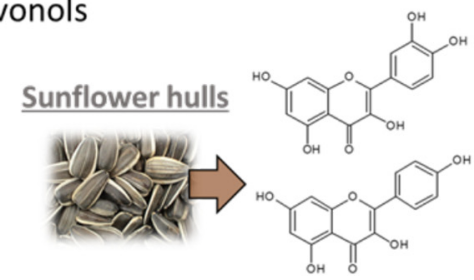

Flavonols

Fig. 1. Different phenolic compounds in the kernels and hulls of rapeseed and sunflower seeds.

meal's proteins and concomitantly valorized the phenolic fraction. Hence, we decided to focus our study on (i) the impact of the desolventization process on the biochemical composition of the meals, (ii) the separation process of the simple phenolic compounds from the meals, (iii) the production of phenolic acids from the meals and (iv) the potential valorization routes of the phenolic fractions.

(i) Conventionally, toasting process using live steam allows the removal of the residual solvent in meals after the solvent assisted oil extraction but also induced the deactivation or elimination of some antinutritional factors such as endogenous enzymes and glucosinolates (Salazar-Villanea et al., 2016; Wildermuth et al., 2016). However, these thermal treatments can also reduce the nutritional qualities of proteins (Salazar-Villanea et al., 2016, 2017) and modified the bioactive properties and concentration of simple phenolic compounds (Zago et al., 2015b). Thus, during this project, we produced different rapeseed and sunflower samples (meals, kernels, hulls) under different desolventization/toasting conditions to study the impact of the process on different biochemical parameters (protein content, protein solubility, total simple phenolic compounds content (TSPC), complex polyphenolic content). (ii) Then, we were interested in the development of novel and green processes for the extraction of the simple phenolic compounds fraction of RSM and SFM samples. Indeed, classical procedures for the recovery of such molecules are based solid-liquid extraction with organic (and sometimes toxic) solvents (Naczk and Shahidi, 2004; Stalikas, 2007; Pérez-Serradilla and Luque de Castro, 2011). However, these methods generally do not leave intact the other components of the raw materials, they are expensive in energy, reagents and solvents, and require the treatment of effluents (Barakat and Rouau, 2014). Consequently, various extraction techniques were studied for the separation of simple phenolic compounds from the different meals, including novel dry fractionation processes or solvents assisted extractions with hydro-alcoholic mixtures. (iii) Afterwards, the enzymatic release of sinapic acid (SA) and caffeic acid (CA) from RSM and SFM, respectively, with different carboxylic esters hydrolases from Aspergillus niger was evaluated. (iv) Finally, the potential valorization routes of phenolic acids (either in pure form or after chemical modification) and some interesting fractions produced after the separation steps were evaluated to be used as antioxidants or tanning agents, respectively.

The results presented in the following sections are from several articles, either already published or in preparation for others. Readers are therefore invited to refer to the corresponding papers for more information and details.

\section{Biochemical composition of the different raw materials used in the PHENOLEO project}

During this project, different RSM and SFM samples were produced under different conditions (Laguna, 2019, Fig. 2). Firstly, the whole rapeseed and sunflower seeds were crushed and de-oiled at room temperature to produce a cake. Then, the residual lipids of the produced cakes were extracted by hexane under the conditions described in Figure 2A. Furthermore, to remove hexane in meals after the oil extraction, a desolventization step was performed under mild conditions $\left(-0.87 \mathrm{bar},>60^{\circ} \mathrm{C}\right)$ to produce an untoasted rapeseed meal (U-RSM) and an untoasted sunflower meal (U-SFM) or, after desolventization, meals were toasted in 

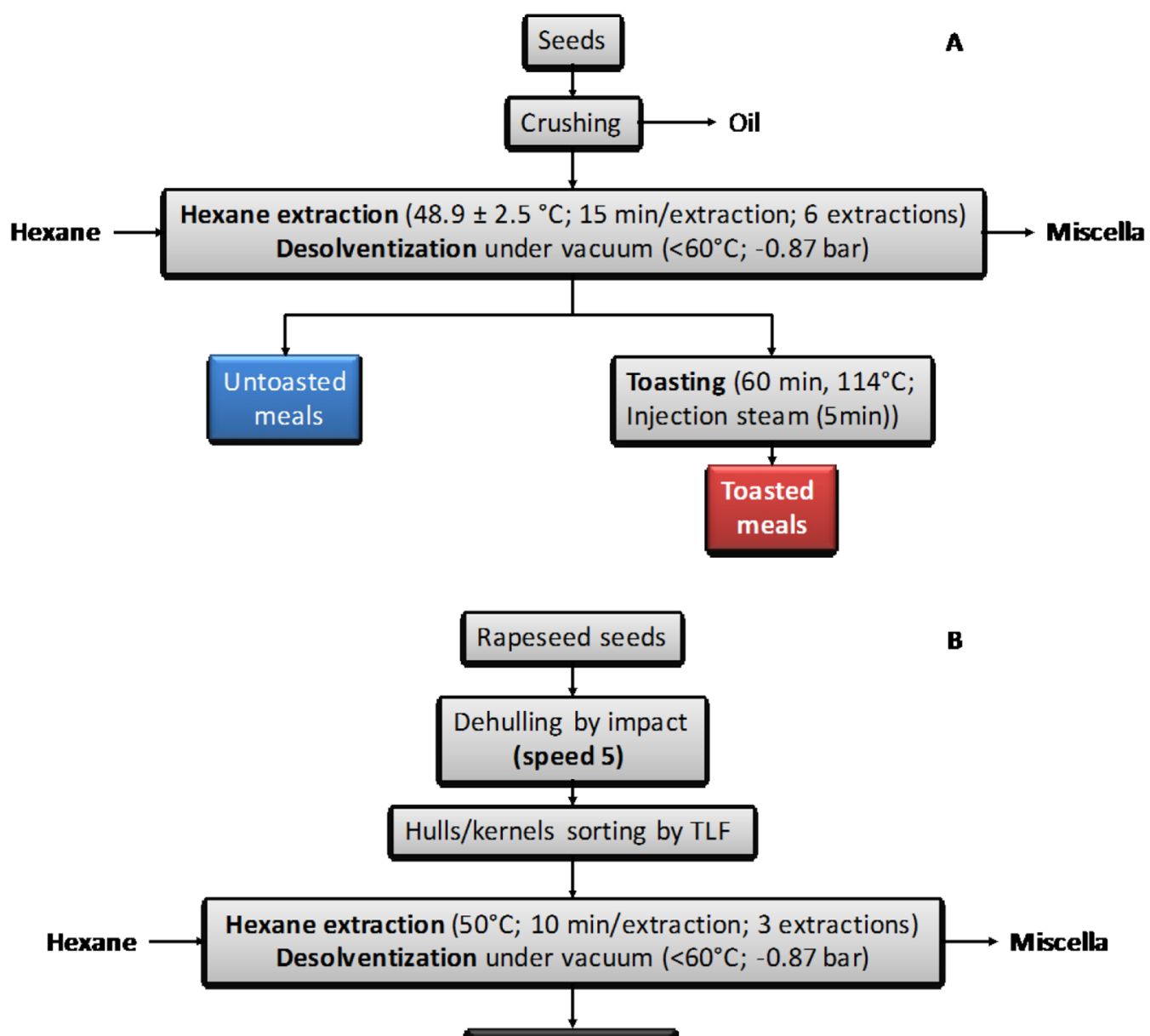

Rapeseed hulls

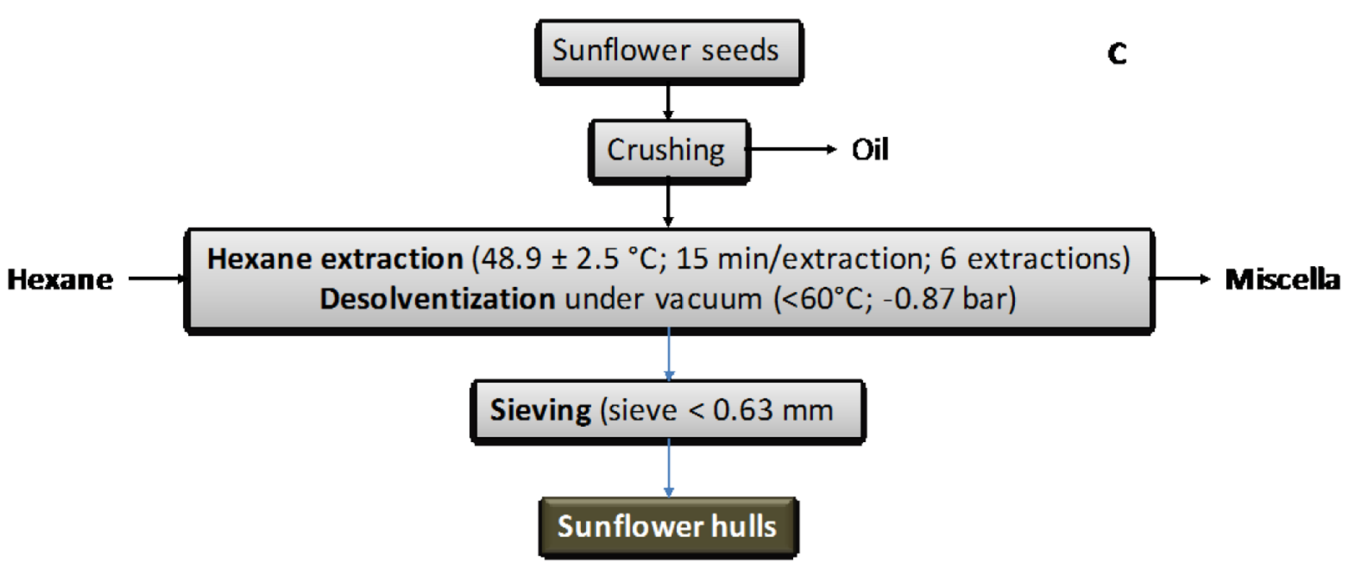

Fig. 2. Production process of untoasted meals and toasted meals (A), untoasted rapeseed hulls (B) and untoasted sunflower hulls (C).

harsh conditions $\left(114^{\circ} \mathrm{C}, 60 \mathrm{~min}\right.$ with an injection steam for $5 \mathrm{~min}$ ) similar to the ones used at industrial scale, to produce a toasted rapeseed meal (T-RSM) and a toasted sunflower meal (T-SFM). Afterwards, different biochemical parameters were determined to evaluate the impact of the different processes performed on meal samples.

\subsection{Proteins, simple phenolic compounds and glucosinolate contents}

The protein content obtained for all RSM and SFM samples were around 38\% DDM and 32\% DDM respectively (Tab. 1) and they were in good agreement with literature data (González-Pérez and Vereijken, 2007; Carré et al., 2016). 
Table 1. Biochemical composition of the raw materials produced during the PHENOLEO project.

\begin{tabular}{lllll}
\hline Sample & Protein content (\% DDM) & Protein solubility $(\%)$ & GSL $(\mu$ mol/g DDM) & TSPC (\% DDM) \\
\hline T-RSM & 38.5 & 55.1 & 5.0 & 1.0 \\
U-RSM & 38.4 & 84.4 & 12.5 & 1.7 \\
U-RSM-kernels & 43.5 & 37.9 & 20.0 & 2.0 \\
U-RSM-hulls & 16.4 & 35.6 & - & 0.1 \\
T-SFM & 33.9 & 83.0 & - & 1.5 \\
U-SFM & 31.8 & 86.2 & - & 2.6 \\
U-SFM-kernels & 50.9 & 85.8 & - & 4.2 \\
U-SFM-hulls & 16.7 & 67.1 & 0.2 \\
\hline
\end{tabular}

Note: $\mathrm{T}=$ toasted, $\mathrm{U}=$ untoasted, $\mathrm{RSM}=$ rapeseed meal, $\mathrm{SFM}=$ sunflower meal, $\mathrm{GSL}=$ glucosinolate, $\mathrm{TSPC}=$ total simple phenolic compounds. Results are means of at least 3 measurements with coefficients of variation $<10 \%$.

Thus, these results clearly demonstrated that extreme temperatures used during the toasting step did not change the protein content of the meals. Moreover, this recalcitrant aspect of proteins has already been observed in other studies where it was demonstrated that desolventization/toasting steps applied on RSM did not affect its protein content (Mosenthin et al., 2016; Salazar-Villanea et al., 2016).

However, either for RSM or SFM samples, a loss of protein solubility in soda (34.7 and 3.7\% respectively) was observed after the toasting step (Tab. 1). This can be explained by the possible modification of techno-functional properties of proteins due to the harsh implemented conditions (SalazarVillanea et al., 2016). Indeed, according to Salazar-Villanea et al. (2017), reduction of protein solubility in RSM is linked to physical (aggregation phenomenon) and chemical (Maillard reactions) modifications of their structures, which lead to a decrease of their digestibility and solubility. Furthermore, these modifications reduce the uses of these meals in feed applications. Regarding this matter, mild desolventization conditions are more suitable for the removing of residual solvent (after the solvent-assisted oil extraction step), while reducing the deterioration of protein quality in meals.

The total simple phenolic compound (TSPC) of RSM and SFM samples was determined by HPLC-DAD as described by Laguna et al. (2018). Here, only the simple and extractable phenolics were determined and not the hardly extractable or bound polyphenols. Thus, it was noticed that the TSPC content of RSM and SFM was reduced by $38.2 \%$ and $40.7 \%$ respectively after the toasting step (Tab. 1). Besides, in the case of RSM, the toasting led to a $60.1 \%$ reduction of the initial glucosinolate (GSL) content. Indeed, as demonstrated by Jensen et al. (1995) and Zago et al. (2015b), phenolic compounds and GSL are thermolabile molecules and the toasting step might be advantageous to eliminate these unwanted anti-nutritional factors. Furthermore, thermal process might also lead to the deactivation of endogenous enzymes, such as myrosinase, that catalyzed the hydrolysis of GSL into toxic molecules (Newkirk and Classen, 2002).

In view of these results, it was demonstrated the advantages and drawbacks of the toasting step applied on RSM and SFM. Nevertheless, knowing that the main objective of the PHENOLEO project was the valorization of the phenolic fraction present in these meals, we decided to continue our work with the untoasted meals containing a net higher TSPC content. Besides, the protein solubility (in soda) of the untoasted meals was higher and more suitable for food and feed uses because of their higher solubility and digestibility.

Finally, hulls of U-RSM and U-SFM were separated from kernels and their different biochemical parameters were determined (Figs. 2B and 2C, Tab. 1). As expected, proteins, simple phenolic compounds and GSL (only for RSM samples) were more concentrated in kernels and these results were in good agreement with literature data (González-Pérez and Vereijken, 2007; Weisz et al., 2009; Fang et al., 2012; Carré et al., 2016).

\subsection{Individual simple phenolic compounds}

The individual phenolic compounds of U-RSM and U-SFM were identified by HPLC-DAD-MS, retention time of authentic standards or literature data as described by Laguna et al. (2018) and results can be seen in Tables 2 and 3. For U-RSM, nineteen different phenolic compounds were identified (Tab. 2). The main phenolic compound was sinapine (SNP), the choline ester of sinapic acid, accounting over $75 \%$ of TSPC content. The other compounds identified were transsinapic acid (SA) and sinapic acid esters comprising sugar (glucose, gentobioside) and/or flavonoid (kaempferol) moieties. For U-SFM, eleven different phenolic compounds were identified (Tab. 3), the main being the 4- and 5-Ocaffeoylquinic acids (4- and 5-CQA) which were co-eluted and quantified together ( $68 \%$ of all the phenolics). Furthermore, 3-O-caffeoylquinic and di-caffeoylquinic acid isomers were also detected. These results were in good agreement with literature data (Weisz et al., 2009; Khattab et al., 2010).

\subsection{Complex bound polyphenolic compounds}

Bound polyphenolic compounds still remain largely unexplored because they are difficult to extract in regular solvents. They likely correspond to oxidized condensed tannins in more or less polymerized forms and potentially exhibiting covalent linkages with macromolecules of the hulls (i.e. cell-wall complex polysaccharides and proteins) as it was mentioned in previous work (Auger et al., 2010). Knowing this, we performed the analysis of bound polyphenolic compounds in rapeseed and sunflower untoasted hulls 
Table 2. MS data of phenolic compounds detected in U-RSM methanolic extract (from Laguna et al., 2018).

\begin{tabular}{lllll}
\hline Compound & $\lambda$ max & {$[\mathrm{M}-\mathrm{H}]^{-} \mathrm{m} / z$} & {$[\mathrm{M}+\mathrm{H}]^{+} \mathrm{m} / z$} & Name \\
\hline 1 & 328 & 294 & 310 & Sinapine \\
2 & 328 & 771 & n.d. & Kaempferol-3-O-sophoroside-7-O- $b$-glucopyranoside \\
3 & 332 & 385 & 207 & Sinapoyl glucopyranoside \\
4 & 333 & 977 & 979 & Sinapoyl-Kaempferol derivative 1 \\
5 & 327 & 520 & n.d. & n.d. \\
6 & 323 & 547 & 665 & n.d. \\
7 & 307 & 494 & 496 & Cyclic spermidine \\
8 & 328 & 237 & 207 & Sinapoyl-Kaempferol derivative 2 \\
9 & 323 & 223 & 207 & Trans-sinapic acid \\
10 & 323 & 223 & 207 & Cis-sinapic acid \\
11 & 332 & 977 & 979 & Kaempferol-di-hexoside-sinapoyl-hexoside \\
12 & 330 & 753 & 777 & Disinapoyl gentiobioside isomer 1 \\
13 & 328 & 753 & 777 & Disinapoyl gentiobioside isomer 2 \\
14 & 327 & 977 & 979 & Sinapoyl-Kaempferol derivative 3 \\
15 & 330 & 591 & 369 & Disinapoyl glucopyranoside \\
16 & 327 & n.d. & n.d. & Trisinapoyl gentiobioside isomer 1 \\
17 & 326 & 959 & 737 & Trisinapoyl gentiobioside isomer 2 \\
18 & 328 & 959 & 737 & Trisinapoyl gentiobioside isomer 3 \\
19 & 328 & 959 & 737 & \\
\hline
\end{tabular}

Note: U-RSM = untoasted rapeseed meal.

Table 3. Phenolic compounds detected in U-SFM methanolic extract (from Laguna et al., 2018).

\begin{tabular}{lll}
\hline Compound & $\lambda \max$ & Name \\
\hline 1 & 327 & 3- $O$-caffeoylquinic acid \\
2 & 326 & 4- $O$ - and 5-O-caffeoylquinic acid \\
3 & 323 & Caffeic acid \\
4 & 327 & n.d. \\
5 & 327 & n.d. \\
6 & 327 & 5- $O$ - $p$-coumaroylquinic acid \\
7 & 329 & 5- $O$-feruloylquinic acid \\
8 & 326 & 3,4-di- $O$-caffeoylquinic acid \\
9 & 328 & 3,5-di- $O$-caffeoylquinic acid \\
10 & 327 & n.d. \\
11 & 328 & 4,5-di- $O$-caffeoylquinic acid \\
\hline
\end{tabular}

Note: U-SFM= untoasted sunflower meal.

(U-hulls) by applying the acidolysis reaction according to two different procedures ( $\mathrm{Yu}$ et al., manuscript in preparation). Firstly, butanol- $\mathrm{HCl}$ assay was applied following the Porter's reaction conditions (Porter et al., 1985). Considering sunflower hulls, no red coloration of the reaction medium was observed suggesting that this material do not contain any condensed tannins. In contrast, rapeseed hulls butanol-HCl reaction medium exhibited a pronounced red coloration that clearly indicated the presence of condensed tannins.

Secondly, rapeseed hulls were submitted to the phloroglucinolysis reaction coupled to reversed phase HPLC analysis according to the method of Kennedy and Jones (2001). The HPLC-UV-MS analysis of the pholoroglucinolysis medium unambiguously revealed the presence of the flavanyl epicatechin-phloroglucinol adduct at $\mathrm{m} / \mathrm{z} 413$ confirming the presence of condensed tannins (i.e. procyanidin oligomers and/ or polymers) as constituent of rapeseed hulls. In order to get optimized quantitative data related to those condensed tannins, the phloroglucinolysis reaction conditions were optimized for rapeseed hulls for incubation temperature, reaction duration and hydrochloric acid concentration applying an experimental design processed by response surface methodology.

The response surface methodology showed that the maximum of $5.4 \mathrm{~g}$ of procyanidins $/ \mathrm{kg}$ of rapeseed U-hulls was predicted with $0.8 \mathrm{M}$ of $\mathrm{HCl}$ at $60^{\circ} \mathrm{C}$ during $30 \mathrm{~min}$ incubation (Unpublished results). Interestingly, the analysis of the phloroglucinolysis reaction media by LC/MS and LC/MS/ MS allowed the identification of some oxidation markers of tannins. These molecules were detected on the full MS chromatogram by their molecular ions at $\mathrm{m} / \mathrm{z} 699$ and the corresponding product ions consistent with the presence of an intramolecular A-type bonds between two adjacent "epicatechin" units in the overall structure of the tannins as already detected in the case of oxidized apple procyanidins (Millet et al., 2019). On the other hand, the phloroglucinolysis method did not allow the identification of any polyphenolic compound in the U-hulls of SFM, indicating that phenolics are mainly present in the form of simple phenolic located in the kernel.

Finally, after the determination of the different biochemical parameters of the different meals, we were interested in the separation of their simple phenolic compounds by applying different separation methodologies, such as dry fractionation processes or solvent assisted extraction with hydro-alcoholic mixtures.

\section{Extraction of the simple phenolic compounds present in the untoasted meals}

\subsection{Dry fractionation processes of the untoasted meals}

Dry milling combined with dry fractionation technologies are new alternative processes that allow the separation of 
Table 4. Size, yield and composition of U-RSM and U-SFM samples obtained by milling with different grids (from Laguna et al., 2018).

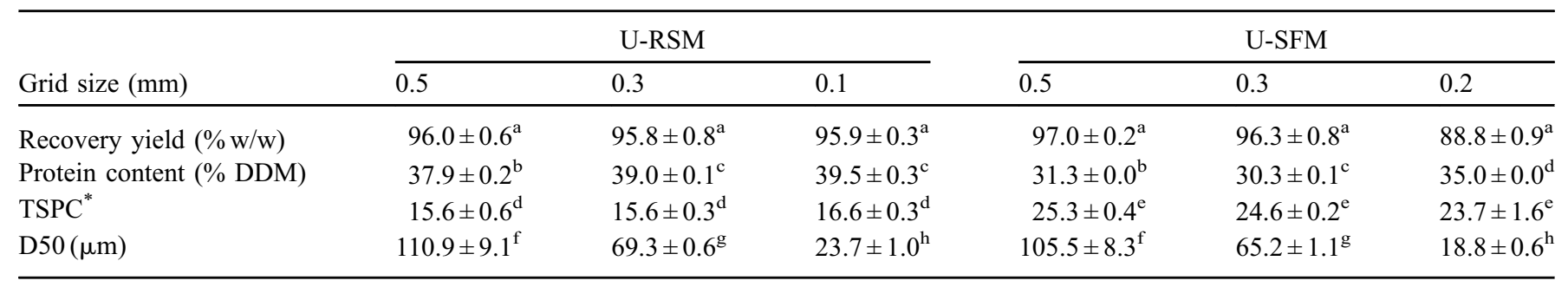

Note: TSPC: total simple phenolic compound. *: TSPC was expressed in mg of sinapic acid equivalent (SAE)/g of defatted dry matter (DDM) and $\mathrm{mg}$ of chlorogenic acid equivalent (CAE)/g DDM for U-RSM and U-SFM respectively. For each raw material, values followed by same superscript letters are not significantly different, $p \leq 0.05$. Values are mean $\pm \mathrm{SD}(n=3)$.

certain macromolecules of interest from different agricultural materials without the use of solvents. These dry fractionation processes emerged as eco-friendly technologies suitable for the concentration of proteins, cellulose, lignin and polyphenols with retained (native) functionality. Knowing this, we tried to separate the simple phenolic compounds from proteins in U-RSM and U-SFM by performing dry fractionation processes (Laguna et al., 2018).

\subsubsection{Effect of the ultrafine milling on the untoasted meals composition}

Firstly, the untoasted meals were milled by shear and impact using an UPZ miller device. Furthermore, to obtain different particles sizes, three different grid were used: $0.5 \mathrm{~mm}$, $0.3 \mathrm{~mm}$ and $0.1 \mathrm{~mm}(0.2 \mathrm{~mm}$ for the U-SFM) and the different ultrafine meals produced were named U-RSM-"size of the grid" and U-SFM-"size of the grid". As expected, the effect of the milling step was different between U-RSM and U-SFM. Indeed, the reduction of the grid size was accompanied by a slight, but significantly, increase by $4 \%$ in the protein content in U-RSM-0.1 (39.5 $\pm 0.3 \%$ DDM, Tab. 4) but this increase was particularly higher in the case of U-SFM-0.2 $(11 \%$ increase, $35.0 \pm 0.0 \%$ DDM, Tab. 4). This was explained by a loss of hull particles during the milling step by a fouling effect. Besides, the loss of the hull fraction in U-SFM- 0.2 also explained it low recovery yield $(88.8 \pm 0.1 \% \mathrm{w} / \mathrm{w}$, Tab. 4) compared to the other meals (around 96\% w/w, Tab. 4). Finally, it was noticed that the total simple phenolic compound (TSPC) values of the different U-RSM and U-SFM samples were not modified after the milling step (around $16 \mathrm{mg} \mathrm{SAE} / \mathrm{g}$ DDM and $24 \mathrm{mg}$ CAE/g DDM, respectively, Tab. 4).

\subsubsection{Turbo-separation of the ultrafine untoasted rapeseed and sunflower meals}

The samples previously milled were then subjected to a turbo-separation step which allows particles separation according to their size and density. Moreover, three different classifier wheel speeds (3000, 5000 and $7000 \mathrm{rpm})$ were tested and after each separation step, two different fractions were recovered: a fine fraction named $\mathrm{FF}$ and a coarse fraction named CF (Fig. 3A). Firstly, we observed, either for U-RSM or U-SFM samples, that proteins and phenolic compounds were separated together in the same fractions. However, in the case of U-RSM samples, we noticed that protein and TSPC content were similar in the different FF obtained, indicating that there was no qualitative influence of the particle size and the speed of the classifier wheel on the purity of protein/phenolics (Figs. 4A and 4B). However, the best overall recovery yields were obtained in FF fractions from U-RSM-0.1 (Fig. 4C) and the highest protein and TSPC content was obtained at $5000 \mathrm{rpm}(48.7 \pm 0.8 \%$ DDM and $21.4 \pm 0.3 \mathrm{mg}$ of sinapic acid equivalents (SAE)/g DDM, respectively, Tab. 5) with a recovery yield of $40.7 \pm 0.6 \% \mathrm{w} / \mathrm{w}$ (Tab. 5). On the other hand, regarding the fine U-SFM, the higher protein and TSPC content were obtained in FF fractions of U-SFM-0.5 (Figs. 4D and $4 \mathrm{E})$. Also, it is worth mentioning that turbo-separation of U-SFM-0.2 was ineffective because particles were too small and were all recovered in FF (data not shown). The best compromise between purity (in terms of protein/phenolic content) and recovery yield was achieved at $5000 \mathrm{rpm}$ with an increase by $67.4 \%$ in proteins $(51.2 \pm 0.3 \mathrm{~g} / 100 \mathrm{~g}$ DDM, Tab. 5), $53.3 \%$ in TSPC $(39.9 \pm 1.1 \mathrm{mg}$ of chlorogenic acid equivalents (CAE)/g DDM /g DDM, Tab. 5), and a recovery yield of $30.0 \%$ (Tab. 5, Fig. 4F). Moreover, protein and TSPC content of FF of U-RSM-0.1 and U-SFM- 0.5 were equivalent to the values determined in their respective U-kernels (Tab. 5), demonstrating that turbo-separation process allows the production of fine fractions concentrated in kernel particles. Hence, we assumed that in U-RSM-0.1 and U-SFM-0.5 particles enriched with protein/phenolic were dissociated from hulls particles during the milling step and were more easily separated during turbo-separation.

\subsubsection{Electrostatic sorting of the ultrafine untoasted rapeseed and sunflower meals}

The fine meals were also subjected to a single step electrostatic sorting which allows the separation of differently charged or polarized particles under the action of an electric field. Moreover, at the end of the separation step, four different fractions were recovered: a positive fraction (PFe) and a negative fraction (NFe) recovered on the electrodes and a positive fraction $(\mathrm{PFc})$ and a negative fraction $(\mathrm{NFc})$ collected on the jars under the electrodes (Fig. 3B). Regarding proteins and phenolics contents, we noticed that they were again separated in the same fractions, indicating that electrostatic sorting was not able to segregate these molecules. However, regarding U-RSM, the highest increase of $50 \%$ in protein $(59.1 \pm 0.4 \mathrm{~g} / 100 \mathrm{~g}$ DDM $)$ and $55 \%$ in TSPC $(25.8 \pm 0.1 \mathrm{mg}$ $\mathrm{SAE} / \mathrm{g}$ DDM) content was obtained in PFe recovered from U-RSM-0.1 (Tab. 5, Figs. 5A and 5B). On the other hand, 

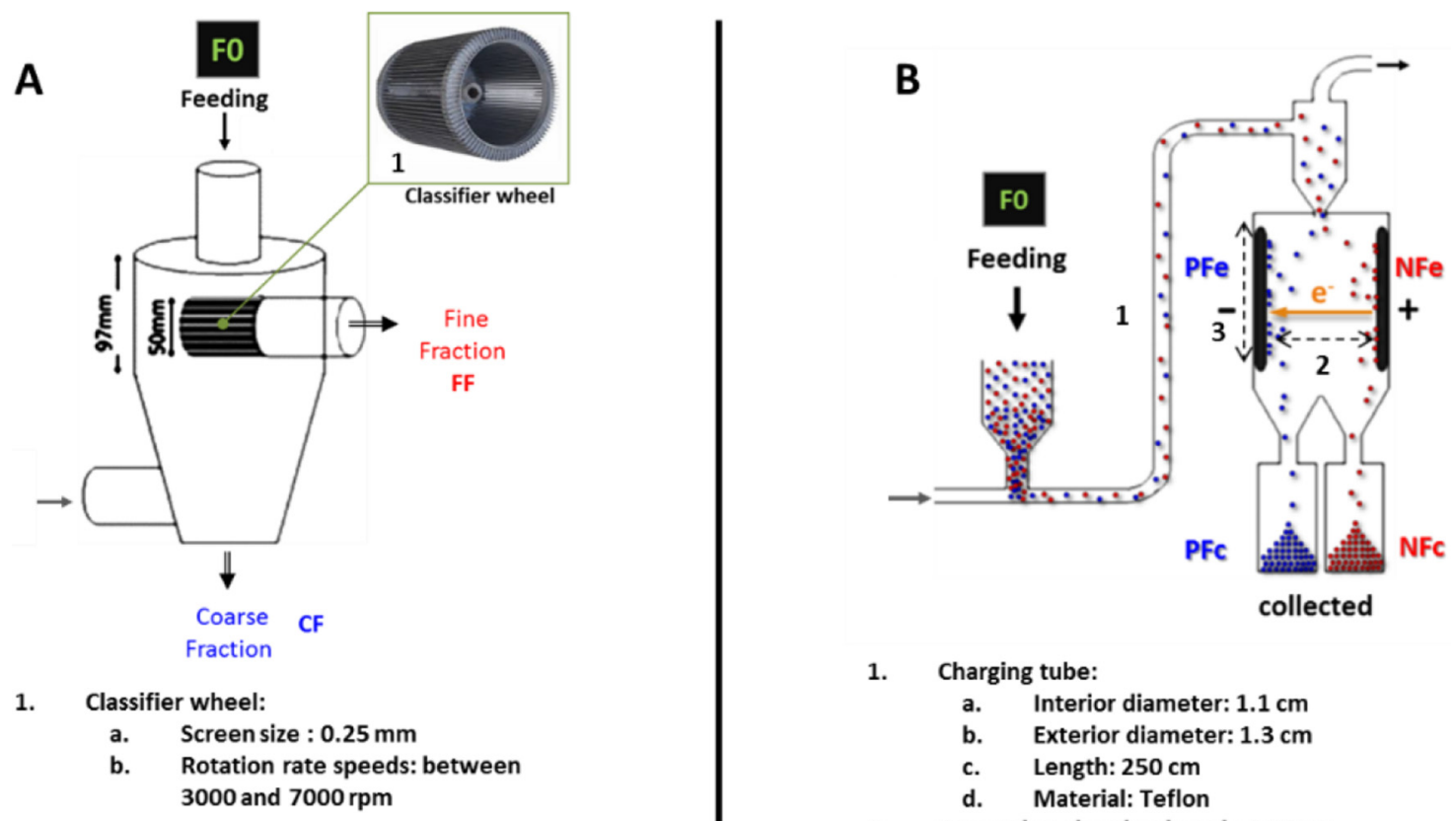

1. Charging tube:

a. Interior diameter: $1.1 \mathrm{~cm}$

b. Exterior diameter: $1.3 \mathrm{~cm}$

c. Length: $250 \mathrm{~cm}$

d. Material: Teflon

2. Separation chamber length: $3.83 \mathrm{~cm}$

3. Electrodes dimensions: $7.5 \mathrm{~cm} \times 28 \mathrm{~cm}$

Fig. 3. Turbo-separation (A) and electrostatic sorting (B) technologies and operating conditions (from Laguna et al., 2018).
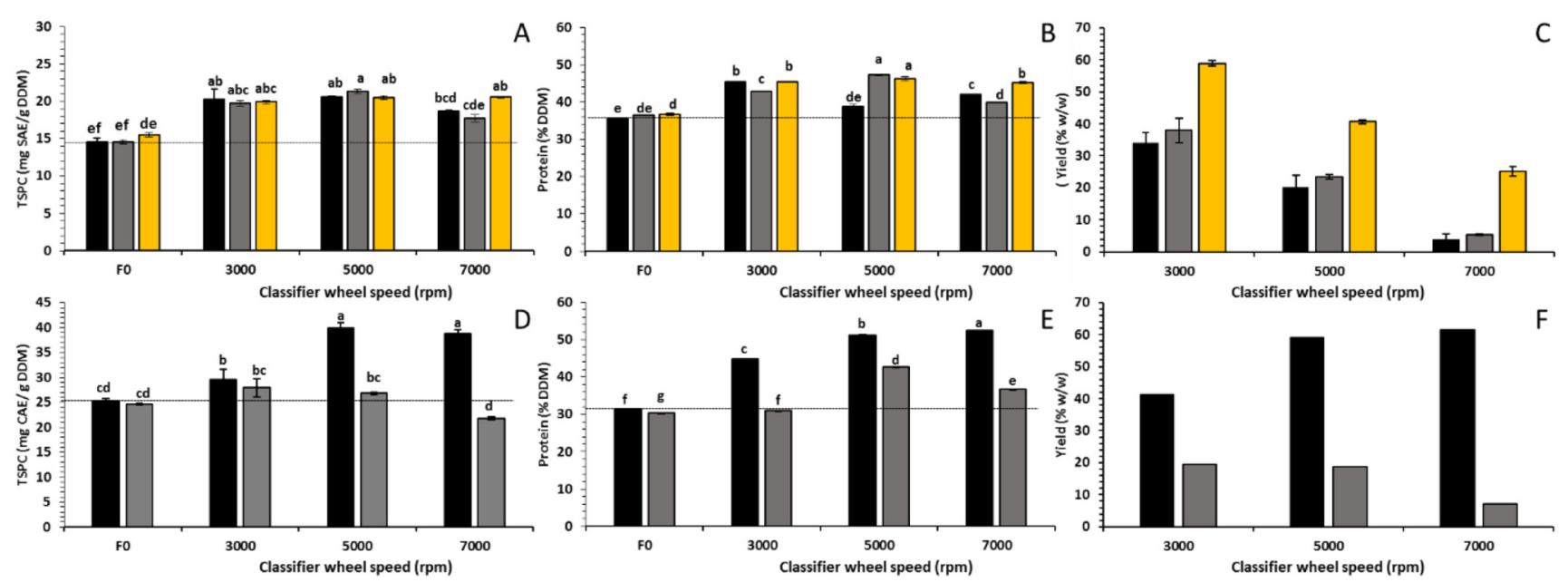

Fig. 4. TSPC, proteins and recovery yields of U-RSM (A, B and C, respectively) and SFM (D, E and F, respectively) fine fractions (FF) after turbo-separation (from Laguna et al., 2018). Grid size (ロ) $0.5 \mathrm{~mm}$; $(\square) 0.3 \mathrm{~mm}$; ( $\square$ ) $0.1 \mathrm{~mm}$. For each material, values followed by same superscript letters are not significantly different, $p \leq 0.05$. Values are means $\pm \operatorname{SD}(n=3)$.

for U-SFM, the highest increase of $96 \%$ in protein $(61.1 \pm 0.0 \mathrm{~g} / 100 \mathrm{~g} \mathrm{DDM})$ and $80 \%$ in TSPC $(45.8 \pm 1.1 \mathrm{mg}$ $\mathrm{CAE} / \mathrm{g} \mathrm{DDM}$ ) content was obtained in $\mathrm{PFe}$ obtained from U-SFM-0.5 (Tab. 5, Figs. 5C and 5D). Moreover, it is worth mentioning that results obtained after U-SFM- 0.2 electrostatic sorting were not taken into account because of the loss in hulls observed during the milling step (Tab. 4). Furthermore, the protein and TSPC content of PFe of U-RSM-0.1 and U-SFM-0.5 were higher than the values determined from their corresponding U-kernel (Tab. 5). Hence, we assumed that the protein bodies associated with phenolic compounds from kernels in U-RSM0.1 and U-SFM-0.5 were more easily charged and concentrated in the respective $\mathrm{PFe}$ fraction after electrostatic sorting. On the other hand, to enhance the low recovery yield of U-RSM-PFe-0.1 and U-SFM-PFe- 0.5 (around 9 and $18 \%$ respectively), multiple recycling steps of the collected fractions (PFc and NFc) were done. Finally, the cumulated recovery yield of U-RSM-PFe- 0.1 and U-SFM-PFe-0.5 increases from 9 to $31 \% \mathrm{w} / \mathrm{w}$ after four cycles and from 18 to $32 \% \mathrm{w} / \mathrm{w}$ after tree cycles, respectively (data not shown).

Here, we showed that electrostatic sorting allowed the recovery of fractions with higher purity in terms of proteins and phenolic compounds compared to turbo-separation. Nevertheless, it can be concluded that the dry fractionation 
Table 5. Physicochemical characterization of untoasted kernels and fractions obtained after electrostatic sorting or turbo-separation of U-RSM and U-SFM (from Laguna et al., 2018).

\begin{tabular}{|c|c|c|c|c|c|c|}
\hline Separation process & \multicolumn{3}{|c|}{ U-RSM-0.1 } & \multicolumn{3}{|c|}{ U-SFM-0.5 } \\
\hline Fraction & $\mathrm{PFe}$ & $\mathrm{FF}^{\S}$ & - & $\mathrm{PFe}$ & $\mathrm{FF}^{\S}$ & - \\
\hline Protein content (\% DDM) & $59.1 \pm 0.4^{\mathrm{c}}$ & $48.7 \pm 0.4^{\mathrm{d}}$ & $48.3 \pm 1.4^{\mathrm{d}}$ & $61.7 \pm 0.0^{\mathrm{c}}$ & $51.2 \pm 0.0^{\mathrm{d}}$ & $52.6 \pm 1.8^{\mathrm{d}}$ \\
\hline Overall recovery Yield $(\% \mathrm{~m} / \mathrm{m})$ & 31.0 & $40.7 \pm 0.6$ & - & 32.0 & 30.0 & - \\
\hline
\end{tabular}

Note: $\mathrm{ES}=$ electrostatic sorting, $\mathrm{TS}=$ turbo-separation, TSPC: total simple phenolic compounds, $\mathrm{U}$-kernels $=$ untoasted kernels, $\mathrm{PFe}=$ positive fraction of the electrode, $\mathrm{FF}=$ fine fraction. *: TSPC was expressed in $\mathrm{mg}$ of sinapic acid equivalent (SAE)/g of defatted dry matter (DDM) and $\mathrm{mg}$ of chlorogenic acid equivalent (CAE)/g DDM for U-RSM and U-SFM respectively. §: Fine fraction (FF) recovered at $5000 \mathrm{rpm}$. For each raw material, values followed by same superscript letters are not significantly different, $p \leq 0.05$. Values are means $\pm \mathrm{SD}(n=3)$.
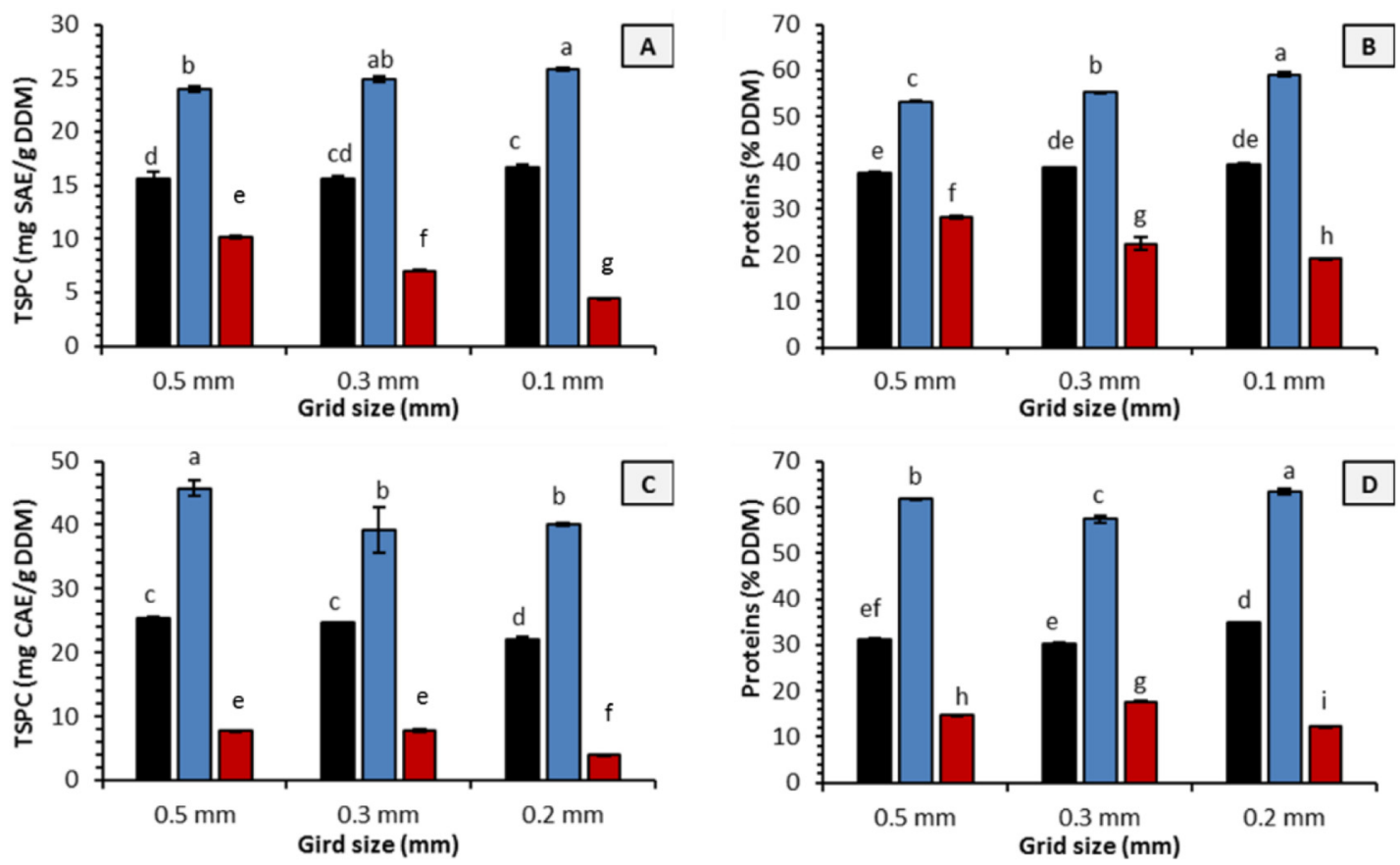

Fig. 5. TSPC, proteins and recovery yields of U-RSM (A and B) and SFM (C and D) fractions after electrostatic sorting: ( $\square$ ) F0, ( $\square)$ PFe, ( $\square)$ NFe (from Laguna et al., 2018). For each material, values followed by same superscript letters are not significantly different, $p \leq 0.05$. Values are means $\pm \mathrm{SD}(n=3)$.

processes are not able to individually separate phenolic compounds from meals. However, dry fractionation processes can be used as a pre-purification step of protein and phenolic compounds from the other constituents of the meals. Finally, protein and phenolic compounds enriched fractions obtained in this work might also be used to different ends. Indeed, as already pointed out by other authors, the associations of proteins and phenolic compounds might act as emulsifiers displaying strong antioxidant activities.

\subsection{Hydro-alcoholic assisted extraction of the simple phenolic compounds from the untoasted meals}

Regarding the extraction of simple phenolic compounds from RSM and SFM, different studies have shown that methanol is the best solvent for their extraction (Pedrosa et al., 2000; Cai and Arntfield, 2001; Weisz et al., 2009). However, methanol is also considered as toxic and non-suitable for food and feed uses. Therefore, we decided to explore the use of more environmentally friendly mixtures such as water-ethanol and water-isopropanol for the extraction of simple phenolic compounds present in U-RSM and U-SFM (Laguna, 2019). Moreover, as U-RSM-0.1 and U-SFM-0.5 allowed the best separation in Section 2.1, these two materials were selected for this purpose.

Hence, simple phenolic compounds were extracted with mixtures of ethanol or isopropanol containing different amounts of water $(5-25 \% \mathrm{v} / \mathrm{v})$. Regarding U-RSM-0.1, either for ethanol or isopropanol, the extraction of simple phenolic compounds was enhanced with increasing the water concentration until a maximum of $15 \%$ was reached (Fig. 6A). 
A

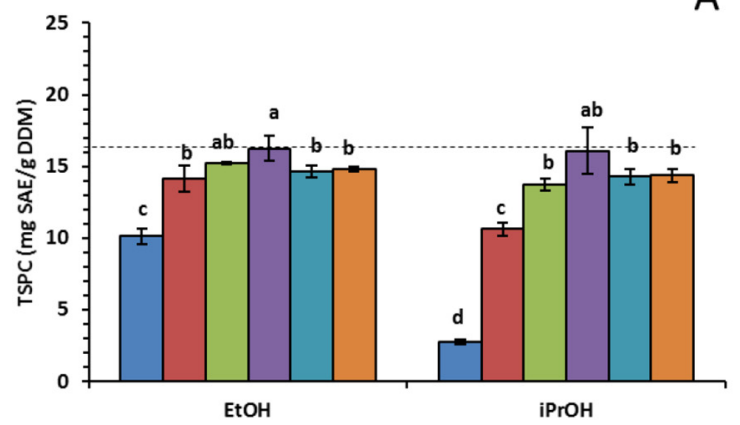

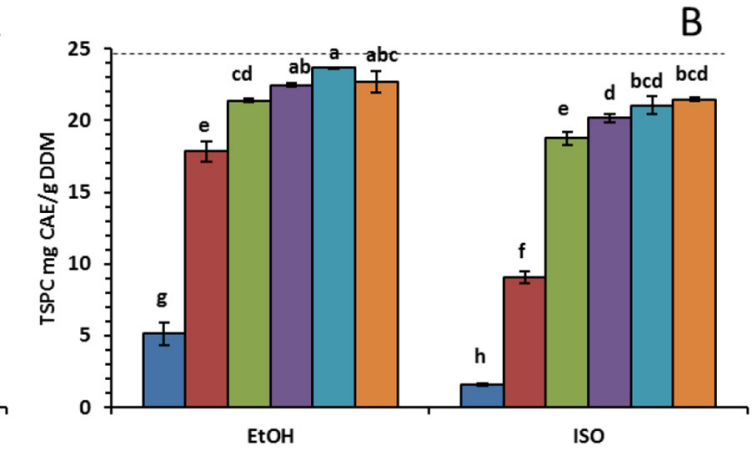

Fig. 6. Simples phenolic compounds extraction of U-RSM (A) and U-SFM (B) with different ethanol and isopropanol hydro-alcoholic mixtures with different water concentration: $0 \%(\square), 5 \%(\square), 10 \%(\square), 15 \%(\square), 20 \%(\square)$ et $25 \%(\square)$ (from Laguna, 2019). Values are mean \pm SD $(n=3$ ). Values followed by same superscript letters are not significantly different, $p \leq 0.05$. Black doted lines represent the total simple phenolic compound (TSPC) values after methanolic extraction.

As a result, the TSPC values obtained with $85 \%$ ethanol and $85 \%$ isopropanol were of $16.3 \pm 0.9 \mathrm{mg} \mathrm{SAE} / \mathrm{g} \mathrm{DDM}$ and $16.1 \pm 1.6 \mathrm{mg} \mathrm{SAE} / \mathrm{g}$ DDM respectively. Furthermore, these results were in the same range of the TSPC value obtained with pure methanol $(16.6 \pm 0.3 \mathrm{mg} \mathrm{SAE} / \mathrm{g} \mathrm{DDM})$.

However, for U-SFM-0.5, the higher TSPC content of $23.7 \pm 0.1 \mathrm{mg} \mathrm{CAE} / \mathrm{g}$ DDM was obtained with ethanol at a water concentration of $20 \%$ (Fig. 6B) and this value was slightly lower than the TSPC content obtained with pure methanol $(25.3 \pm 0.4 \mathrm{mg} \mathrm{CAE} / \mathrm{g} \mathrm{DDM}$, Tab. 4). Finally, regarding the extraction with isopropanol, a maximum was never reached whatever the water concentration tested in this study and the highest TSPC content of $21.5 \pm 0.1 \mathrm{mg} \mathrm{CAE} / \mathrm{g}$ DDM was obtained with $25 \%$ of water.

Thus, these results showed the efficiency of different hydro-alcoholic mixtures for the recovery of simple phenolic compounds present in U-RSM and U-SFM. Moreover, knowing that ethanol is a green bio-based solvent, their hydro-alcoholic mixtures could be considered as the best choice for the extraction of these bioactive molecules. However, adding water might also led to the extraction of other undesirable compounds such as minerals, peptides or sugars, leading to tedious and complex purification steps for the recovery of pure phenolic compounds. Thus, it is of paramount importance to determine the specificity of these solvents towards other molecules present in the meals before concluding on their efficiency. Furthermore, knowing that the use of ethanol in RSM altered its protein solubility and amino acid composition (Kalaydzhiev et al., 2020), it is necessary to study the impact of the process presented in this work on the quality of the protein fraction in U-RSM and U-SFM.

\section{Enzymatic treatments of RSM and SFM samples to produce phenolic acids}

It has been well documented in numerous studies that phenolic acids have interesting bioactive properties, such as antioxidants, anti-UV and antimicrobial activities (Shahidi and Ambigaipalan, 2015; Ouerghemmi et al., 2017; Gullón et al., 2018). Moreover, phenolic acids could also be used for the production of new additives or polymers precursors (Aouf et al., 2012; Zago et al., 2015a; Hollande et al., 2018).
Consequently, rapeseed and sunflower meals could be advantageously used as sources of phenolic acids. Regarding this matter, we aimed to produce sinapic acid (SA) and caffeic acid (CA) from RSM and SFM samples, respectively, by performing enzymatic treatments with various fungal carboxylic ester hydrolases from recombinant Aspergillus niger strains (Laguna, 2019; Laguna et al., 2019). For SFM samples, we tested an $A$. niger type-B recombinant feruloyl esterase (AnFaeB) and a recombinant $A$. niger chlorogenate esterase (ChlE) because of their hydrolytic activity on caffeic acid esters (CAEsters) (Ramos-de-la-Peña and Contreras-Esquivel, 2016). On the other hand, A. niger type-A recombinant feruloyl esterase (AnFaeA) was used for the hydrolysis of sinapic acid esters (SAEsters) in RSM samples because of their hydrolytic activity regarding these molecules (Faulds, 2010; Gopalan et al., 2015). Moreover, enzymatic treatments were done either directly on crude meals or on their dry methanolic extract, mainly composed of simple phenolics compounds, minerals and carbohydrates (Sripad and Narasinga Rao, 1987) but devoid of proteins. Furthermore, we used both toasted and untoasted meals because, as pointed out before, untoasted meals have a higher phenolic content than the corresponding toasted ones (Tab. 1), while thermal treatments performed during the toasting step might have deactivated endogenous enzymes that could disturb enzymatic hydrolysis.

\subsection{Release of free caffeic acid from toasted SFM (T-SFM), untoasted SFM (U-SFM) and its methanolic dry extract with AnFaeB and ChIE}

The enzymatic treatments were performed under optimal $\mathrm{pH}$ (6.0), temperature $\left(50^{\circ} \mathrm{C}\right)$ and enzyme concentration (30 nkat/g and $10 \mathrm{nkat} / \mathrm{g}$ for $\mathrm{AnFaeB}$ and ChlE, respectively) for the complete hydrolysis of all the CAEsters present in sunflower samples. Moreover, the total simple phenolic content was expressed as total caffeic acid derivatives (TCAD) content since $95 \%$ of SFM phenolics were found as caffeic acid esters (Weisz et al., 2009; Karamać et al., 2012).

Regarding the use of AnFaeB in T-SFM, it allowed an $100 \%$ hydrolysis yield after $3 \mathrm{~h}$ incubation (Tab. 6, Supplementary Material Fig. S1A). On the other hand, the highest hydrolysis yield obtained with ChlE was $90 \%$ after $4 \mathrm{~h}$ 
Table 6. Maximal amount and yield of caffeic acid (CA) after enzymatic treatment of T-SFM and U-SFM dry methanolic extract with ChlE and AnFaeB (from Laguna et al., 2019).

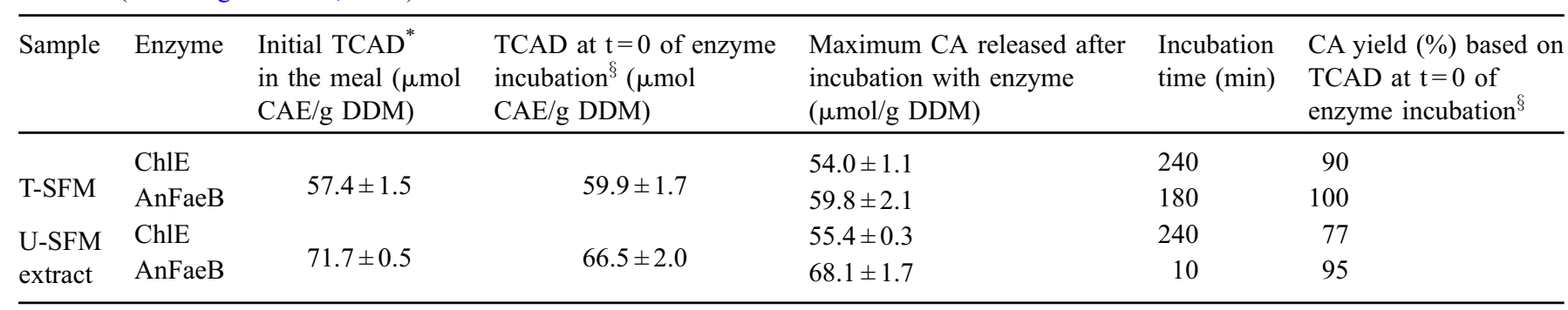

Note: *: TCAD = total caffeic acid derivatives; $\mathrm{CAE}=$ caffeic acid equivalent. $\mathrm{DDM}=$ defatted dry matter. Values are mean $\pm \mathrm{SD}(n=2) . \S$ : The substrate was pre-incubated for $30 \mathrm{~min}$ in MOPS buffer at $50^{\circ} \mathrm{C}$ before adding enzyme $(\mathrm{t}=0$ of enzyme incubation).

incubation (Tab. 6). Compared to AnFaeB, this lower value of free $\mathrm{CA}$ released by ChlE was mainly due to the incomplete hydrolysis of 4-CQA and 5-CQA and the complete inability to hydrolyse 3-CQA (Supplementary Material Fig. S1B). Finally, either with AnFaeB or ChlE, the TCAD content was unchanged during the different incubation times (around $58 \mu \mathrm{mol}$ of caffeic acid derivatives (CaAE)/g DDM, data not shown).

Surprisingly, a strong decrease in the TCAD content over time $(>30 \%)$ was observed with or without enzyme (control) in U-SFM (data not shown). This decrease was attributed to the presence of endogenous polyphenol oxidases (PPO, $1.02 \pm 0.08 \mathrm{nkat} / \mathrm{mL}$ diphenol oxidase activity and $0.43 \mathrm{nkat} / \mathrm{mL}$ \pm 0.02 monophenol oxidase activity) in this untoasted meal that degraded $\mathrm{CA}$ and its derivatives during the pre-incubation and incubation steps. This constituted a major drawback that greatly limited the value of U-SFM as a substrate for in situ enzymatic production of CA.

To overcome this issue, the enzymatic treatment was performed on its dry methanolic extract. Here, all CAEsters were hydrolysed into free CA by AnFaeB after only $10 \mathrm{~min}$, leading to a $95 \%$ hydrolysis yield (Tab. 6). This result was slightly lower than the $100 \%$ hydrolysis yield obtained in T-SFM. However, the net higher initial TCAD content in U-SFM methanolic extract led to a higher free CA production than in T-SFM $(68.1 \pm 1.7$ and $59.8 \pm 2.1 \mu \mathrm{mol} / \mathrm{g}$ DDM respectively, Tab. 6). On the other hand, when hydrolysis was performed with ChlE, the hydrolysis of 4-CQA and 5-CQA were more slowly and not completely converted into CA after $240 \mathrm{~min}$ (data not shown). Besides, only a small fraction of 3-CQA was hydrolysed. This typical feature of ChlE already observed during T-SFM hydrolysis could explain why the hydrolysis yield was lower, corresponding to only $77 \%$ (Tab. 6). Finally, either with AnFaeB or ChlE, only a slight decrease in the TCAD content was noticed over enzymatic incubation time on methanolic extracts, meaning that phenolic-degrading enzymes (i.e. PPO) in meal were not extracted with methanol.

\subsection{Release of free sinapic acid from RSM samples with AnFaeA}

The treatments were performed under optimal $\mathrm{pH}(5.5)$, temperature $\left(55^{\circ} \mathrm{C}\right)$ and enzyme concentration $(39 \mathrm{nkat} / \mathrm{g})$ for the complete hydrolysis of all the SAEsters present in rapeseed samples. Moreover, the total phenolic content of RSM samples was expressed as total sinapic acid derivatives (TSAD) content because $98 \%$ of their phenolics were shown to be sinapic acid esters (Khattab et al., 2010; Siger et al., 2013).

The maximum hydrolysis yield of around 70 and $78 \%$ was obtained after $240 \mathrm{~min}$ incubation for T-RSM and U-RSM respectively (Tab. 7) and almost all sinapine, mono- and disinapoyl glucose isomers were hydrolysed at the end of incubation (Supplementary Material Fig. S2A). However, AnFaeA only partially managed to hydrolyse kaempferolbased sinapic acid derivatives, as well as di-sinapoyl gentiobiosides and some tri-sinapoyl gentiobiosides (Supplementary Material Fig. S2A). Furthermore, regarding the initial TSAD content present in U-RSM, a loss of $16 \%$ was observed after the 30 min pre-incubation step (before adding the enzyme in the medium, Tab. 7). Again, this loss was related to the possible endogenous PPO activity present in U-RSM. In addition, TSAD content was unchanged during T-RSM hydrolysis, assuming that possible endogenous enzymes were deactivated during toasting.

As previously, the enzymatic hydrolysis was performed on the dry methanolic extract of U-RSM and, surprisingly, the hydrolysis yield was only 55\% (Tab. 7, Supplementary Material Fig. S2B). Moreover, it was observed the appearance of a new phenolic compound in the reaction medium (Supplementary Material Fig. S2B, compound 8) and according to the mass and NMR $\left({ }^{1} \mathrm{H},{ }^{13} \mathrm{C}\right)$ spectra, it was identified as 1,2-di- $O$-sinapoyl- $\beta$-D-glucose (Supplementary Material Figs. S3 and S4). This new phenolic compound might result from transesterification of sinapine (or mono-sinapoyl glucose isomers) with the glucose molecules present in the extract. Regarding this matter, most feruloyl esterases displays a classical Ser-His-Asp catalytic triad when it performs transesterification with ferulic acid esters via the formation and subsequent breakdown of a covalent acyl-enzyme intermediate (Prates et al., 2001; Dilokpimol et al., 2016; Kelle et al., 2016) and it is reasonable to presume that it will be the same for sinapine (or mono-sinapoyl glucose isomers) in the presence of AnFaeA in the buffered extract of U-RSM. A possible catalytic mechanism of action is proposed in Supplementary Material, Figure S5. On the other hand, regarding the TSAD content, it remained higher and constant during hydrolysis kinetics (around 59.2 $\mu \mathrm{mol}$ SAE/DDM, data not shown). Thus, this might indirectly confirm the presence of phenolic-degrading enzymes (i.e. PPO for instance) in U-RSM that were not extracted with methanol. 
Table 7. Maximal amount and yield of sinapic acid (SA) after enzymatic treatment of T-RSM, U-RSM and U-RSM dry methanolic extract with AnFaeA (from Laguna et al., 2019).

\begin{tabular}{lllll}
\hline Sample & $\begin{array}{l}\text { Initial TSAD }{ }^{*} \text { in the } \\
\text { meal }(\mu \mathrm{mol} \mathrm{SAE} / \mathrm{g} \text { DDM })\end{array}$ & $\begin{array}{l}\text { TSAD at } \mathrm{t}=0 \text { of } \\
\text { enzyme incubation } \\
(\mu \mathrm{mol} \mathrm{SAE} / \mathrm{g} D \mathrm{DM})\end{array}$ & $\begin{array}{l}\text { Maximum SA released after 240 min } \\
\text { incubation with enzyme }(\mu \mathrm{mol} / \mathrm{g} \text { DDM) }\end{array}$ & $\begin{array}{l}\text { SA yield (\%) based } \\
\text { on TCAD at } \mathrm{t}=0 \text { of } \\
\text { enzyme incubation }^{\S}\end{array}$ \\
\hline T-RSM & $46.0 \pm 0.3$ & $44.8 \pm 0.2$ & $31.6 \pm 0.1$ & 70 \\
U-RSM & & $53.1 \pm 1.0$ & $41.3 \pm 0.3$ & 78 \\
U-RSM & $64.2 \pm 1.2$ & $59.2 \pm 2.3$ & $32.3 \pm 0.4$ & 55 \\
extract & & & \\
\hline
\end{tabular}

Note: *: TSAD = total sinapic acid derivatives; $\mathrm{SAE}=$ sinapic acid equivalent. DDM = defatted dry matter. Values are mean $\pm \mathrm{SD}(n=2) . \oint$ The substrate was pre-incubated for $30 \mathrm{~min}$ in MOPS buffer at $55^{\circ} \mathrm{C}$ before adding enzyme $(\mathrm{t}=0$ of enzyme incubation).

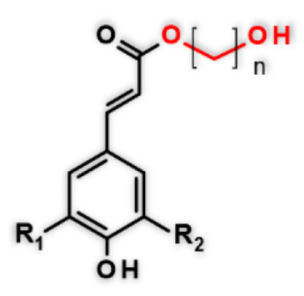

A

Hydroxy alkyl esters of sinapic acid: $R_{1}=R_{2}=O M e$
Hydroxy alkyl esters of caffeic acid $R_{1}=O H, R_{2}=H$

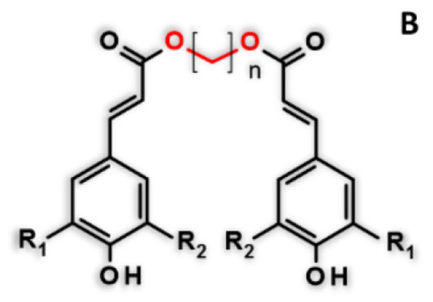

Bis-aryl esters of sinapic acid: $\mathbf{R}_{\mathbf{1}}=\mathbf{R}_{\mathbf{2}}=\mathrm{OMe}$

Bis-aryl esters of caffeic acid: $\mathbf{R}_{1}=\mathbf{O H}, \mathbf{R}_{2}=\mathbf{H}$

Fig. 7. Hydroxyalkyl esters of sinapic acid and caffeic acid (A) and bis-aryl esters of sinapic acid and caffeic acid (B).

In view of these results, we demonstrate the ability of various fungal carboxylic ester hydrolases to hydrolyse the different phenolic esters present in RSM and SFM samples. However, from all the substrates tested for enzymatic hydrolysis, U-SFM methanolic extract and U-RSM showed the best compromise between initial TSAD or TCAD content, hydrolysis yields and released CA or SA amounts. Finally, in order to develop a sustainable and efficient green process, it would be beneficial to use the ethanol/water mixtures previously studied in Section 2.2 to recover the phenolic compounds from the meals, instead of methanol.

\section{Valorization of enriched protein/phenolic fractions produced after dry fractionation processes of U-RSM and U-SFM}

Here, the potential valorization routes of the previously hydrolysed phenolic acid and some interesting fractions produced after the separation steps were evaluated.

\subsection{Synthesis of novel hydroxyalkyl esters and bis-aryl esters from sinapic acid and caffeic acid and evaluation of their antioxidant activity in and oil-in- water emulsion}

It is well known that the esterification of phenolic acids with aliphatic alcohols of adequate chain-length improved their antioxidant activity in heterophasic lipid systems (oil-inwater emulsions, liposomes, etc.) and even in cultured cells (Laguerre et al., 2010; Bayrasy et al., 2013; Sørensen et al., 2014). This phenomenon, related to the "cut-off effect", was attributed to a better location and concentration of the lipophilic phenolic esters at the interfacial phase where lipid oxidation occurs. Thus, we were interested in the chemical synthesis of novel hydroxyalkyl esters $\left(\mathrm{R}-\mathrm{O}-\left(\mathrm{CH}_{2}\right)_{\mathrm{n}}-\mathrm{OH}\right)$ and bis-aryl esters $\left(\mathrm{R}-\mathrm{O}-\left(\mathrm{CH}_{2}\right)_{\mathrm{n}}-\mathrm{O}-\mathrm{R}\right)$, from sinapic acid or caffeic acids and aliphatic $\alpha, \omega$-diols $\left(\mathrm{OH}-\left(\mathrm{CH}_{2}\right)_{\mathrm{n}}-\mathrm{OH}\right)$ of increasing chain length from 2 to 12 carbon atoms (Fig. 7), and the evaluation of their antioxidant activities (Laguna et al., 2020). Here, we studied the impact of the presence of the hydroxyl group or the second phenolic unit at the end of the alkyl chain of hydroxy alkyl esters or bis-aryl esters respectively on their antioxidant activities in an oil-in-water emulsion model. Furthermore, SA and CA were selected because, as previously observed in Section 3, they can be easily recovered from U-RSM and U-SFM after enzymatic treatments.

To determine the antioxidant activity of the different molecules in an oil-in-water emulsion, we decided to perform the conjugated autoxidizable triene (CAT) assay as described by (Laguerre et al., 2008). Regarding sinapic and caffeic hydroxyalkyl esters, their antioxidant activities were in the same range or lowered compared to their corresponding initial phenolic acid (data not shown). These results implied that there was a negative influence of the polar hydroxyl group at the end of the alkyl chain of the hydroxyalkyl esters in their 
Table 8. Net productions of ammonia ( $\mathrm{mg} /$ tube) and isovalerate (mmoles/tube) from U-RSM- 0.1 and U-SFM- 0.5 fraction and culture medium final pH (from Broudiscou et al., 2020).

\begin{tabular}{|c|c|c|c|c|c|c|}
\hline & \multicolumn{3}{|c|}{ U-RSM-PFe-0.1 } & \multicolumn{3}{|c|}{ U-SFM-PFe-0.5 } \\
\hline $\operatorname{Pr}>\mathrm{F}$ model & 0.0083 & 0.21 & 0.0003 & 0.019 & 0.0079 & 0.0059 \\
\hline $\mathrm{R}^{2}$ & 0.95 & 0.71 & 0.99 & 0.92 & 0.95 & 0.95 \\
\hline SRD & 0.092 & 8.97 & 0.025 & 0.183 & 4.54 & 0.052 \\
\hline Source & \multicolumn{6}{|c|}{ Probability $\operatorname{Pr}>F$} \\
\hline Treatment & \multicolumn{6}{|c|}{ Means per treatment $(N=3)$} \\
\hline $\mathrm{CO}$ & $-0.622(0.033)$ & $-8.0(0.71)$ & $6.08(0.93)$ & $0.15(0.070)$ & $-14.8(0.064)$ & $6.16(0.51)$ \\
\hline $\mathrm{HO}$ & $-0.194(0.20)$ & $-5.7(0.53)$ & $6.08(0.76)$ & $0.88(0.20)$ & $-12.6(0.11)$ & $6.12(0.20)$ \\
\hline $\mathrm{CT}$ & -0.339 & -13.4 & 6.09 & 0.59 & -3.3 & 6.21 \\
\hline
\end{tabular}

Note: IC5: isovalerate; $\mathrm{NH}_{3}$ : ammonia; RSD: residual standard deviation; comparison of cold and hot pretreatments (CO and HO) with control (CT): the first-order errors are in brackets.

antioxidant activities in the model emulsion system. Indeed, these molecules containing two hydrophilic groups and separated by an apolar skeleton are different than classical phenolipids containing one hydrophilic head and a hydrophobic tail. Thus, it is strongly suspected that the decrease in the antioxidant activity observed in this study was related to the negative effect of the hydroxyl group at the end of the alkyl chain. Moreover, this - $\mathrm{OH}$ group could possibly affect the orientation at the interface and/or the distribution of hydroxyalkyl esters in the different phases of the emulsion.

On the other hand, an improvement of the antioxidant activity was observed for the two bis-aryl esters series until an optimum was reached with the bis-aryl esters containing a short alkyl chain between their phenolic moieties (data not shown). This phenomenon, named the "cut-off" effect, has already been observed in numerous lipophilized phenolic acids series (Sørensen et al., 2014; González et al., 2015; GrajedaIglesias et al., 2016). However, despite the presence of two phenolic moieties in their structure, their antioxidant activity was never doubled compared to that of their corresponding phenolic acid. From our point of view, the significant difference obtained in our study might be due to the position of the second phenolic moiety in the structure of bis-aryl esters, and self-organization phenomena through " $\pi$-stacking" intramolecular interactions (" $p$ " orbitals overlap between two aromatic cycles).

In view of these results, one could assume that it would be theoretically more efficient to use twice as much phenolic acid than bis-aryl esters. However, to validate this assumption, additional experiments are still required to assess the effect of surfactant type and concentration in emulsions and to determine physical properties of bis-aryl ester and their partitioning in the emulsion. Finally, numerous perspectives of application of these bis-aryl esters can also be foreseen, as for instance in the field of materials, as additives or precursors of polymers for the production of packaging with antioxidant properties.

\subsection{Self-tanning of untoasted rapeseed and sunflower meals fraction produced by dry fractionation processes}

Phenolic compounds present in rapeseed meal and sunflower meal samples have been studied for their ability to interact with proteins that might lead to the reduction of their simulated degradation by rumen microorganisms (Wischer et al., 2013; Bongartz et al., 2018). Thus, we aim to quantify the impact of treatments - hot or cold and at basic $\mathrm{pH}-$ on the rumen degradability of proteins in rapeseed and sunflower positive fraction of the electrodes (PFe of U-RSM-0.1 and U-SFM-0.5) previously obtained after electrostatic-sorting in Section 2.1.2 (Broudiscou et al., 2020). Indeed, these fractions, enriched with proteins and simple phenolics, are suitable raw materials for studying the protein tanning ability of endogenous phenolic compounds. Hence, using this potential property of self-tanning, these fractions would limit the amounts of formaldehyde implemented during tanning or they could be directly incorporated into the diet of ruminants.

Here, two incubation conditions were study: (i) one at high temperature $\left(50^{\circ} \mathrm{C}\right)$ with a meal fraction:water mixture of $1: 2$ (w/w) during $48 \mathrm{~h}$ and the other one at (ii) low temperature $\left(4{ }^{\circ} \mathrm{C}\right)$ with a meal fraction:water mixture of $(1: 10)(\mathrm{w} / \mathrm{w})$ at $\mathrm{pH}$ 9.0 for $48 \mathrm{~h}$. Moreover, microbial proteolysis on meal fractions were quantified during $24 \mathrm{~h}$ in rumen batch fermentations. In the case of the U-RSM-PFe-0.1, the net production of ammonia $\left(\mathrm{NH}_{3}\right)$ and isovalerate (IC5) produced by the decarboxylation of the carbon chains of leucine and isoleucine was negative (Tab. 8), indicating that the fermentations associated with the experimental substrate induced a consumption of ammonia by microorganisms greater than its release. However, the cold pretreatment had the tendency to increase this difference, whereas pretreatment at $50{ }^{\circ} \mathrm{C}$ did not have any effect (Tab. 8). Thus, the action of the cold pretreatment can be attributed to a lower degradation of RSM proteins rather than an increase in microbial protein synthesis. 
Regarding U-SFM-PFe-0.5, both pretreatments did not significantly modify the production of ammonia and isovalerate (Tab. 8). However, the trend was similar to that observed with U-RSM-PFe- 0.1 and the cold pretreatment was associated with the lower ammonia production. In conclusion, only the cold and alkaline pretreatment allowed to decrease the microbial proteolysis of the fractions from RSM and SFM. Nevertheless, the proportion was too small to provide a nutritional advantage in feeding ruminants.

\section{Conclusions and perspectives}

Nowadays, rapeseed and sunflower meals are mainly used as animal feed because of their high concentration in protein but they can also be used as a potential source of bioactive natural phenolic compounds. Consequently, any type of process allowing the recovery of phenolic compounds without degradation of other constituents (such as proteins), and the production of meals with improved nutritional value would be beneficial for the oilseed industry. Regarding this matter, in order to obtain proteins with high quality from rapeseed and sunflower meals, we demonstrated that it is necessary to use mild conditions during the desolventization steps. Furthermore, it also allows to conserve higher quantities of phenolic compounds. Moreover, dry fractionation has shown its interest as a pre-purification process for rapeseed and sunflower meals. Regarding this matter, selftanning by cold treatment of the rapeseed and sunflower meal fractions, obtained by electrostatic sorting and enriched with proteins/phenolic compounds, made it possible to reduce the microbial proteolytic activity in vitro and therefore led to a tanning effect. Yet, despite these interesting results, dry fractionation could not separate phenolic compounds from proteins, the only available solution remaining solvent extraction. Regarding this point, we demonstrated that it could be possible to use mixtures based on water and ethanol in substitution for methanol, and as effective as the latter in extracting phenolic compounds. In this way, it would be interesting to consider the use of ethanol to replace hexane during the extraction of the residual oil after pressing the seeds. Moreover, the co-extraction of oil and phenolic compounds from meals with ethanol and the suitable amount of water could lead to the simultaneous recovery of the oil, the hydro-alcoholic phase containing the phenolic compounds and the delipidated and dephenolized meals enriched with proteins. These resulting meals could be then used to obtain fractions enriched only with protein by performing dry fractionation processes. On the other hand, once extracted the phenolic fraction, we proved that it could serve as a source of free bioactive phenolic acids by using different fungal carboxylic ester hydrolases. Later on, sinapic acid and caffeic acid were esterified to produced novel bis-aryl esters with strong antioxidant activities. In view of these results, the PHENOLEO project has demonstrated that rapeseed and sunflower meals could be integrated in a green process of biorefinery for the recovery of their bioactive phenolic compounds. However, there are still many parameters that need to be explored before concluding on the efficiency of the different processes presented here, such as the impact on the techno-functional properties and the amino acid profile of the different fractions after dry fractionation processes or enzymatic hydrolysis and their feasibility on a larger scale, in particular in terms of energy costs and expenses, aspects that were not addressed in this work. Finally, regarding the production of bis-aryl esters, chemical synthesis is not likely the most suitable from an environmental point of view. Accordingly, in order to develop a sustainable and efficient process, it would be interesting to test the enzymes that we have used for the hydrolysis of phenolic esters in Section 4 and in particular AnFaeA which has shown an acyl transfer activity.

\section{Supplementary Material}

Figure S1. Chromatograms obtained after enzymatic hydrolysis of U-SFM with 30 nkat AnFaeB/g DDM (A) and 10 nkat $\mathrm{ChlE} / \mathrm{g}$ DDM (B) at $\mathrm{t}=0 \mathrm{~min}(\mathrm{red})$ and $\mathrm{t}=240 \mathrm{~min}$ (black) at $326 \mathrm{~nm}$. 3-O-caffeoylquinic acid (3-CQA) (1), 4-O-caffeoylquinic acid (4-CQA) (2), 5-O-caffeoylquinic acid (5-CQA) (3), caffeic acid (4), 5-O-coumaroylquinic acid (5-CoQA) (5), 5-Oferuloylquinic acid (5-FQA) (6), 3,5-Di-O-caffeoylquinic (3,5-diCQA) (7) and 4,5-Di-O-caffeoylquinic (3,5-diCQA) (4,5-diCQA) (8). From Laguna (2019).

Figure S2. Chromatograms obtained after enzymatic hydrolysis of U-RSM (A) and U-RSM dry methanolic extract (B) with 39 nkat AnFaeA/g DDM at $\mathrm{t}=0 \mathrm{~min}(\mathrm{red})$ and $\mathrm{t}=240 \mathrm{~min}$ (black) at $323 \mathrm{~nm}$. Sinapoyl-kaempferol derivatives (1), sinapine (SNP) (2), trans-sinapic acid (SA) (3), cis-sinapic acid (SA) (4), di-sinapoyl derivatives (5), Tri-sinapoyl derivatives (6), sinapoyl glucose (7) and 1,2-di-O-sinapoyl$\beta$-D-glucose (8). From Laguna (2019).

Figure S3. Chemical structure and NMR ${ }^{1} \mathrm{H}$ and ${ }^{13} \mathrm{C}$ data of 1,2-di-O-sinapoyl-b-D-glucose. From Laguna et al. (2019).

Figure S4. Chemical structure and LC-MS data of 1,2-di-Osinapoyl-b-D-glucose. From Laguna et al. (2019).

Figure S5. Possible mechanism for the formation of 1,2-di-Osinapoyl-b-D-glucose by transesterification of sinapine with 1-O-sinapoyl-b-D-glucose catalyzed by AnFaeA. Note: Mechanism adapted from Dilokpimol et al. (2016).

The Supplementary Material is available at http://www.ocljournal.org/10.1051/ocl/2020056/olm.

\section{Funding sources}

This work was performed, in partnership with the SAS PIVERT, within the frame of the French Institute for the Energy Transition (Institut pour la Transition Energétique (ITE) P.I.V.E.R.T. (https://sas-pivert.com/) selected as an Investment for the Future ("Investissements d'Avenir"). This work was supported, as part of the Investments for the Future, by the French Government under the reference ANR-001-01.

Acknowledgments. The results presented in Section 4 come from a work in collaboration with Dr Anne Lomascolo and her team (INRA, Aix Marseille Univ, UMR1163 BBF, Biodiversité et Biotechnologie Fongiques, Marseille, France) that we warmly thank here. 


\section{References}

Amarowicz R, Naczk M, Shahidi F. 2000. Antioxidant activity of crude tannins of canola and rapeseed hulls. J Am Oil Chem Soc 77: 957-961.

Aouf C, Lecomte J, Villeneuve P, Dubreucq E, Fulcrand H. 2012. Chemo-enzymatic functionalization of gallic and vanillic acids: synthesis of bio-based epoxy resins prepolymers. Green Chem 14: 2328.

Aouf C, Zago E, Lecomte J, et al. 2016. Polyaromatic dimers, method for preparing same and use of same. Patent WO2016/097657.

Auger B, Marnet N, Gautier V, et al. 2010. A detailed survey of seed coat flavonoids in developing seeds of Brassica napus L. J Agric Food Chem 58: 6246-6256.

Barakat A, Rouau X. 2014. New dry technology of environmentally friendly biomass refinery: glucose yield and energy efficiency. Biotechnol Biofuels 7: 138.

Barry TN. 1976. The effectiveness of formaldehyde treatment in protecting dietary protein from rumen microbial degradation. Proc Nutr Soc 35: 221-229.

Baumert A, Milkowski C, Schmidt J, Nimtz M, Wray V, Strack D. 2005. Formation of a complex pattern of sinapate esters in Brassica napus seeds, catalyzed by enzymes of a serine carboxypeptidase-like acyltransferase family? Phytochemistry 66: 1334-1345.

Bayrasy C, Chabi B, Laguerre M, et al. 2013. Boosting antioxidants by lipophilization: a strategy to increase cell uptake and target mitochondria. Pharm Res 30: 1979-1989.

Bongartz V, Böttger C, Wilhelmy N, Schulze-Kaysers N, Südekum KH, Schieber A. 2018. Protection of protein from ruminal degradation by alkali-induced oxidation of chlorogenic acid in sunflower meal. J Anim Physiol Anim Nutr 102: e209-e215.

Borredon M-E, Berger M, Dauguet S, et al. 2011. Débouchés actuels et futures du tournesol produit en France-Critères de qualité. Innov Agron 14: 19-38.

Broudiscou L-P, Laguna O, Lecomte J, Solé-Jamault V, Dauguet S. 2020. Methods assessment of self-tanning of rapeseed and sunflower meal fractions enriched in proteins and phenolic compounds using in vitro measurement of protein rumen degradability. OCL 27: 1.

Cai R, Arntfield SD. 2001. A rapid high-performance liquid chromatographic method for the determination of sinapine and sinapic acid in canola seed and meal. J Am Oil Chem Soc 78: 903910.

Carré P, Citeau M, Robin G, Estorges M. 2016. Hull content and chemical composition of whole seeds, hulls and germs in cultivars of rapeseed (Brassica napus). OCL 23: A302.

Dilokpimol A, Mäkelä MR, Aguilar-Pontes MV, Benoit-Gelber I, Hildén KS, de Vries RP. 2016. Diversity of fungal feruloyl esterases: updated phylogenetic classification, properties, and industrial applications. Biotechnol Biofuels 9: 231.

Dimitrios B. 2006. Sources of natural phenolic antioxidants. Trends Food Sci Technol 17: 505-512.

Diot-Néant F, Migeot L, Hollande L, Reano FA, Domenek S, Allais F. 2017. Biocatalytic synthesis and polymerization via ROMP of new biobased phenolic monomers: a greener process toward sustainable antioxidant polymers. Front Chem 5: 126.

Fang J, Reichelt M, Hidalgo W, Agnolet S, Schneider B. 2012. Tissuespecific distribution of secondary metabolites in rapeseed (Brassica napus L.). PLoS ONE 7(10): e48006.

Faulds CB. 2010. What can feruloyl esterases do for us? Phytochem Rev 9: 121-132.
Fine F, Lucas J-L, Chardigny J-M, Redlingshöfer B, Renard M. 2015. Food losses and waste in the French oilcrops sector. OCL 22: A302.

González MJ, Medina I, Maldonado OS, Lucas R, Morales JC. 2015. Antioxidant activity of alkyl gallates and glycosyl alkyl gallates in fish oil in water emulsions: Relevance of their surface active properties and of the type of emulsifier. Food Chem 183: 190-196.

González-Pérez S, Vereijken JM. 2007. Sunflower proteins: overview of their physicochemical, structural and functional properties. J Sci Food Agric 87: 2173-

Gopalan N, Rodríguez-Duran LV, Saucedo-Castaneda G, Nampoothiri KM. 2015. Review on technological and scientific aspects of feruloyl esterases: A versatile enzyme for biorefining of biomass. Bioresour Technol 193: 534-544.

Grajeda-Iglesias C, Salas E, Barouh N, Baréa B, Panya A, FigueroaEspinoza MC. 2016. Antioxidant activity of protocatechuates evaluated by DPPH, ORAC, and CAT methods. Food Chem 194: 749-757.

Gullón B, Eibes G, Moreira MT, Herrera R, Labidi J, Gullón P. 2018. Yerba mate waste: A sustainable resource of antioxidant compounds. Ind Crops Prod 113: 398-405.

Guo W, Hou Y, Ren S, Tian S, Wu W. 2013. Formation of deep eutectic solvents by phenols and choline chloride and their physical properties. J Chem Eng Data 58: 866-872.

Hernández-Jabalera A, Cortés-Giraldo I, Dávila-Ortíz G, et al. 2015. Influence of peptides-phenolics interaction on the antioxidant profile of protein hydrolysates from Brassica napus. Food Chem 178: $346-357$.

Hollande L, Domenek S, Allais F. 2018. Chemo-enzymatic synthesis of renewable sterically-hindered phenolic antioxidants with tunable polarity from lignocellulose and vegetal oil components. Int J Mol Sci 19: 3358.

Horbury MD, Turner MAP, Peters JS, et al. 2020. Exploring the photochemistry of an ethyl sinapate dimer: an attempt toward a better ultraviolet filter. Front Chem 8: 633.

Ivanova P, Chalova V, Uzunova G, Koleva L, Manolov I. 2016. Biochemical characterization of industrially produced rapeseed meal as a protein source in food industry. Agric Agric Sci Proc 10: $55-62$.

Jensen SK, Liu Y-G, Eggum BO. 1995. The effect of heat treatment on glucosinolates and nutritional value of rapeseed meal in rats. Anim Feed Sci Technol 53: 17-28.

Kalaydzhiev H, Ivanova P, Stoyanova M, et al. 2020. Valorization of rapeseed meal: influence of ethanol antinutrients removal on protein extractability, amino acid composition and fractional profile. Waste Biomass Valoriz 11: 2709-2719.

Karamać M, Kosińska A, Estrella I, Hernández T, Dueñas M. 2012. Antioxidant activity of phenolic compounds identified in sunflower seeds. Eur Food Res Technol 235: 221-230.

Kelle S, Nieter A, Krings U, Zelena K, Linke D, Berger RG. 2016. Heterologous production of a feruloyl esterase from Pleurotus sapidus synthesizing feruloyl-saccharide esters: FAE production from $P$. sapidus synthesizing feruloyl-saccharide esters. Biotechnol Appl Biochem 63: 852-862

Kennedy JA, Jones GP. 2001. Analysis of proanthocyanidin cleavage products following acid-catalysis in the presence of excess phloroglucinol. J Agric Food Chem 49: 1740-1746.

Khattab R, Eskin M, Aliani M, Thiyam U. 2010. Determination of sinapic acid derivatives in canola extracts using high-performance liquid chromatography. $J$ Am Oil Chem Soc 87: 147-155.

Kikuzaki H, Hisamoto M, Hirose K, Akiyama K, Taniguchi H. 2002. Antioxidant properties of ferulic acid and its related compounds. J Agric Food Chem 50: 2161-2168. 
Kreps F, Vrbiková L, Schmidt Š. 2014. Industrial rapeseed and sunflower meal as source of antioxidants. Int J Eng Res Appl 4: $45-54$.

Kumar N, Pruthi V. 2014. Potential applications of ferulic acid from natural sources. Biotechnol Rep 4: 86-93.

Laguerre M, López-Giraldo LJ, Lecomte J, et al. 2008. Conjugated autoxidizable triene (CAT) assay: a novel spectrophotometric method for determination of antioxidant capacity using triacylglycerol as ultraviolet probe. Anal Biochem 380: 282-290.

Laguerre M, López-Giraldo LJ, Lecomte J, et al. 2010. Relationship between hydrophobicity and antioxidant ability of "phenolipids" in emulsion: a parabolic effect of the chain length of rosmarinate esters. J Agric Food Chem 58: 2869-2876.

Laguna O. 2019. Valorisation des composés phénoliques des tourteaux de colza et tournesol: du fractionnement des matières premières vers la synthèse de molécules multifonctionnelles. In: Sciences agricoles. Université Montpellier. Français. NNT: 2019MONTG007. tel-02142245f.

Laguna O, Barakat A, Alhamada H, et al. 2018. Production of proteins and phenolic compounds enriched fractions from rapeseed and sunflower meals by dry fractionation processes. Ind Crops Prod 118: 160-172.

Laguna O, Odinot E, Bisotto A, et al. 2019. Release of phenolic acids from sunflower and rapeseed meals using different carboxylic esters hydrolases from Aspergillus niger. Ind Crops Prod 139: 111579.

Laguna O, Durand E, Baréa B, et al. 2020. Synthesis and evaluation of antioxidant activities of novel hydroxyalkyl esters and bis-aryl esters based on sinapic and caffeic acids. J Agric Food Chem 68: 9308-9318.

Lin F-H, Lin J-Y, Gupta RD, et al. 2005. Ferulic acid stabilizes a solution of vitamins $\mathrm{C}$ and $\mathrm{E}$ and doubles its photoprotection of skin. J Invest Dermatol 125: 826-832.

Milkowski C, Strack D. 2010. Sinapate esters in brassicaceous plants: biochemistry, molecular biology, evolution and metabolic engineering. Planta 232: 19-35.

Millet M, Poupard P, Guilois-Dubois S, Zanchi D, Guyot S. 2019. Self-aggregation of oxidized procyanidins contributes to the formation of heat-reversible haze in apple-based liqueur wine. Food Chem 276: 797-805.

Mosenthin R, Messerschmidt U, Sauer N, Carré P, Quinsac A, Schöne F. 2016. Effect of the desolventizing/toasting process on chemical composition and protein quality of rapeseed meal. J Anim Sci Biotechnol 7: 36.

Naczk M, Shahidi F. 2004. Extraction and analysis of phenolics in food. J Chromatogr A 1054: 95-111.

Newkirk R, Classen H. 2002. The effects of toasting canola meal on body weight, feed conversion efficiency, and mortality in broiler chickens. Poult Sci 81: 815-825.

Ouerghemmi I, Bettaieb Rebey I, Rahali FZ, et al. 2017. Antioxidant and antimicrobial phenolic compounds from extracts of cultivated and wild-grown Tunisian Ruta chalepensis. J Food Drug Anal 25: 350-359.

Ozdal T, Capanoglu E, Altay F. 2013. A review on protein-phenolic interactions and associated changes. Food Res Int 51: 954-970.

Pająk P, Socha R, Gałkowska D, Rożnowski J, Fortuna T. 2014. Phenolic profile and antioxidant activity in selected seeds and sprouts. Food Chem 143: 300-306.

Pedrosa MM, Muzquiz M, García-Vallejo C, et al. 2000. Determination of caffeic and chlorogenic acids and their derivatives in different sunflower seeds. J Sci Food Agric 80: 459-464.

Pérez-Serradilla JA, Luque de Castro MD. 2011. Microwave-assisted extraction of phenolic compounds from wine lees and spraydrying of the extract. Food Chem 124: 1652-1659.
Peyrot C, Mention MM, Brunissen F, Allais F. 2020. Sinapic acid esters: octinoxate substitutes combining suitable uv protection and antioxidant activity. Antioxidants 9: 782.

Porter LJ, Hrstich LN, Chan BG. 1985. The conversion of procyanidins and prodelphinidins to cyanidin and delphinidin. Phytochemistry 25: 223-230.

Prates JAM, Tarbouriech N, Charnock SJ, Fontes CMGA, Ferreira LMA, Davies GJ. 2001. The structure of the feruloyl esterase module of xylanase 10B from clostridium thermocellum provides insights into substrate recognition. Structure 9: 1183-1190.

Ramos-de-la-Peña AM, Contreras-Esquivel JC. 2016. Methods and substrates for feruloyl esterase activity detection, a review. $J \mathrm{Mol}$ Catal B Enzym 130: 74-87.

Reano AF, Chérubin J, Peru AMM, et al. 2015. Structure-activity relationships and structural design optimization of a series of $p$ hydroxycinnamic acids-based bis- and trisphenols as novel sustainable antiradical/antioxidant additives. ACS Sustain Chem Eng 3: 3486-3496.

Salazar-Villanea S, Bruininx EMAM, Gruppen H, et al. 2016. Physical and chemical changes of rapeseed meal proteins during toasting and their effects on in vitro digestibility. J Anim Sci Biotechnol 7:62.

Salazar-Villanea S, Bruininx EMAM, Gruppen H, Carré P, Quinsac A, van der Poel AFB. 2017. Effects of toasting time on digestive hydrolysis of soluble and insoluble 00-rapeseed meal proteins. J Am Oil Chem Soc 94: 619-630.

Shahidi F, Ambigaipalan P. 2015. Phenolics and polyphenolics in foods, beverages and spices: antioxidant activity and health effects - A review. J Funct Foods 18: 820-897.

Siger A, Czubinski J, Dwiecki K, Kachlicki P, Nogala-Kalucka M. 2013. Identification and antioxidant activity of sinapic acid derivatives in Brassica napus L. seed meal extracts: main phenolic compounds in rapeseed. Eur J Lipid Sci Technol 115: $1130-1138$.

Sørensen A-DM, Durand E, Laguerre M, et al. 2014. Antioxidant properties and efficacies of synthesized alkyl caffeates, ferulates, and coumarates. J Agric Food Chem 62: 12553-12562.

Stalikas CD. 2007. Extraction, separation, and detection methods for phenolic acids and flavonoids. J Sep Sci 30: 3268-3295.

Szydłowska-Czerniak A, Trokowski K, Szłyk E. 2011. Optimization of extraction conditions of antioxidants from sunflower shells (Helianthus annuus L.) before and after enzymatic treatment. Ind Crops Prod 33: 123-131.

Terres Inovia, Terres Univia. 2019. Fiche qualité des tourteaux de colza et tournesol. Available from https:/www.terresinovia.fr/ documents/20126/156342/fiche_Terres_Inovia_Terres-Univiaqualite-tourteaux-tournesol_2019.̄pdf/d15 d5574-d28f5173-1883-887e69d6d8f9?t=1576600887168 [last consult: 2020/ 31/08] and https://www.terresinovia.fr/documents/20126/ 156024/fiche_Terres_Inovia_Terres-Univia-qualite-tourteaux-col za_2018V3.pdf/2ee-77fa3-aa3d-82df-a6b6-8ee40453095a?t= $15 \overline{8} 0835151604$ [last consult: 2020/31/08].

Weisz GM, Kammerer DR, Carle R. 2009. Identification and quantification of phenolic compounds from sunflower (Helianthus annuus L.) kernels and shells by HPLC-DAD/ESI-MSn. Food Chem 115: 758-765.

Wildermuth SR, Young EE, Were LM. 2016. Chlorogenic acid oxidation and its reaction with sunflower proteins to form greencolored complexes. Compr Rev Food Sci Food Saf 15: 829-843.

Wischer G, Boguhn J, Steingaß H, Schollenberger M, Rodehutscord M. 2013. Effects of different tannin-rich extracts and rapeseed tannin monomers on methane formation and microbial protein synthesis in vitro. Animal 7: 1796-1805. 
Zago E, Durand E, Barouh N, Lecomte J, Villeneuve P, Aouf C. 2015a. Synthesis of lipophilic antioxidants by a lipase-bcatalyzed addition of peracids to the double bond of 4-vinyl-2methoxyphenol. J Agric Food Chem 63: 9069-9075.
Zago E, Lecomte J, Barouh N, et al. 2015b. Influence of rapeseed meal treatments on its total phenolic content and composition in sinapine, sinapic acid and canolol. Ind Crops Prod 76: 1061-1070.

Cite this article as: Laguna $\mathrm{O}$, Guyot $\mathrm{S}, \mathrm{Yu} \mathrm{X}$, Broudiscou L-P, Chapoutot P, Solé-Jamault V, Anton M, Quinsac A, Sicaire A-G, Fine F, Citeau M, Durand E, Barakat A, Villeneuve P, Lecomte J, Dauguet S. 2020. The PHENOLEO project or how to separate and add-value to phenolic compounds present in rapeseed and sunflower meals. OCL 27: 61. 